Research, part of a Special Feature on Advancing the Understanding of Behavior in Social-Ecological Systems: Results from Lab and Field Experiments

\title{
Irrigation experiments in the lab: trust, environmental variability, and collective action
}

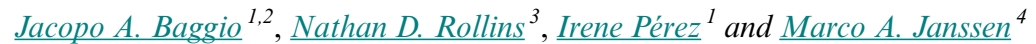

\begin{abstract}
Research on collective action and common-pool resources is extensive. However, little work has concentrated on the effect of variability in resource availability and collective action, especially in the context of asymmetric access to resources. Earlier works have demonstrated that environmental variability often leads to a reduction of collective action in the governance of shared resources. Here we assess how environmental variability may impact collective action. We performed a behavioral experiment involving an irrigation dilemma. In this dilemma participants invested first into a public fund that generated water resources for the group, which were subsequently appropriated by one participant at a time from head end to tail end. The amount of resource generated for the given investment level was determined by a payoff table and a stochastic event representing environmental variability, i.e., rainfall. Results show that that (1) upstream users' behavior is by far the most important variable in determining the outcome of collective action; (2) environmental variability (i.e. risk level in investing in the resource) has little effect on individual investment and extraction levels; and (3) the action-reaction feedback is fundamental in determining the success or failure of communities.
\end{abstract}

Key Words: asymmetry; common-pool resources; feedbacks; laboratory experiments; trust; variability

\section{INTRODUCTION}

A challenge in managing common-pool resources, such as water for irrigation, is how to prevent the free-rider problem, i.e., ensuring that the individual users of a resource all contribute to the allocation and maintenance of the resource and that some don't take advantage of the efforts of others. Collective action is thus especially challenging in systems that are naturally prone to asymmetries caused by differences in power or geographic position. Some individuals are privileged in extracting resources, as seen in irrigation systems. In these systems, asymmetries because of heterogeneity caused by the biophysical context favor free riders (Anderies et al. 2011). A key feature in many of these systems lies in the coupled interactions between the natural processes of the environment and the decisions of the resource users (Anderies et al. 2004). Global environmental change is increasing the level of variability and is therefore increasing risk and uncertainty for natural resource users. In this context, studying the effect of environmental variability on collective action is critical to assessing the sustainability of coupled socialecological systems. Anderies and Janssen (2011) argue that the increase of environmental variability may reduce the ability of resource users to solve collective action problems. To improve our understanding of the interactions between users' decisions about exploiting a resource and variability in the availability of that resource, we performed a simple behavioral experiment.

The experiment focused on irrigation dilemmas, which explore the challenges of asymmetric access to a common resource shared between downstream and upstream users. To resolve the dilemma, upstream participants need to allow water to flow to downstream participants. This is because upstream participants need the cooperation of downstream participants to create the public infrastructure (e.g., irrigation canals) for the irrigation system (Ostrom and Gardner 1993). The irrigation dilemma we propose in this paper has been studied in lab and field experiments (Janssen et al. 2011, 2012, Cardenas et al. 2013). These previous experiments found that (1) participants' initial level of cooperation relates to their trust in the other participants and (2) inequality in the resource extractions can reduce investments into the public infrastructure. Because irrigation systems are developed to cope with variability of rainfall availability, it is a natural extension to study the effect of variability in water provisioning.

Common resource dilemma experiments within social psychology have studied the consequences of environmental variability (e.g., Messick et al. 1988, Rapaport et al. 1992, Biel and Gärling 1995, Wit and Wilke 1998, Au 2004). However, in contrast to the experiments described in this paper, those studies were one-shot games in which environmental variability was related to the size of the resource. In these previous studies, variability increased overharvesting because people overestimated the size of the resource and therefore thought noncooperative behavior was justified (Biel and Gärling 1995). Using this approach, Budescu et al. (1990) performed experiments that introduced asymmetry in payoff rules, in contrast to the asymmetrical access to the resource that we used in our experiment, and found that different positions led to different responses to environmental variability. Individuals with more favorable exchange rates for resource units to earnings reduced their demands for the common resource compared with those who had less favorable exchange rates. Walker and Gardner (1992) introduced environmental variability in a repeated commons dilemma by assuming that more harvesting leads to a higher probability that the current round is the last round of the experiment. In their experiment, environmental variability led to a greater appropriation of the resource. Anderies et al. (2013) studied the effect of disturbances in a computer-based lab experiment on the irrigation dilemma where participants could communicate. They found a very modest negative effect of variability in water availability and

${ }^{1}$ Center for Behavior, Institutions and the Environment, Arizona State University, ${ }^{2}$ Department of Environment and Society, Utah State University, ${ }^{3}$ Center for Behavior, Institutions and the Environment, School of Human Evolution and Social Change, Arizona State University, ${ }^{4}$ Center for Behavior, Institutions and the Environment, School of Sustainability, Arizona State University 
infrastructure decline. However, because participants could communicate in that design, that might have buffered some of the effect of environmental variability.

Based on these studies, we would expect increased variability to lead to reduced cooperation and that other important social metrics, like risk aversion, trust, and upstream users' behavior, would contribute to the observed levels of investment and extraction. We expected that risk-neutral individuals (i.e., participants who showed no preference between options with equal expected payoffs but differing levels of risk) would not take environmental variability into account in the decision-making process. We expected trust to be a significant factor in how participants choose to invest in the public infrastructure, and higher measures of trust from the Trust Game would correspond with higher levels of investment in the Irrigation Game. Upstream users' behavior is also an important, observable metric that accounts for feedback between different rounds and between the investment and extraction phases. An individual may "trust" others to invest in the resource; then, in subsequent rounds, an individual will act based on the observed behavior of upstream users. The behavior of upstream users can be inferred by the downstream users through their collective extraction level, which we model using an equalshare ratio (ESR) metric. In our analysis of the effects of upstream users' behavior, we relied on the ESR and net gains, an heuristic found in many social dilemmas such as ultimatum games (Allison and Messick 1990).

The laboratory experiments reported in this paper built on a prior experimental design in which the participants could not communicate (Janssen et al. 2012). However, in addition to having an asymmetric common-pool resource dilemma without communication, we introduced different levels of investment risk in the form of environmental variability within the experiment. These new variables allowed us to determine if and how different levels of environmental variability affect the level of cooperation, measured as investment into the public infrastructure. Variability seems to decrease the willingness of people to invest in the resource, at least in public good games (see, e.g., Wit and Wilke 1998, Gustafson et al. 2000, Au 2004). However, variability in resource generation in repeated common-pool resources experiments has not been sufficiently studied (but see Anderies et al. 2013 and Walker and Gardner 1992). This is an important extension because climatic change and other global environmental changes affect the variability of the resources that users may depend on; thus, it can potentially have an impact on resource users' behavior.

Our main aim was to assess which factors are most important in influencing collective action at different levels of environmental variability in social-ecological systems with asymmetric access to the common-pool resource. Is environmental variability a decisive factor in assessing investment in common-pool resources, or is it dampened by the observed upstream behavior?

The asymmetric access to the resource, resulting from the sequential extraction decision, leads to unequal resource distribution and unequal earnings. Thus, strategic uncertainty, i.e., regarding investment and extraction choices of others, and observed upstream users' behavior outweigh environmental variability and initial trust levels. The latter finding is in line with Ostrom's claims about the importance of feedback effects between trust and actions based on the observed behavior of others (Ostrom 1998). We were able to assess the latter by implementing a statistical analysis that addressed feedbacks between investment and extraction decisions, taking time into account. Variability affected the level of investment in the resource, thus, the level of collective action, but it had a milder effect compared with upstream behavior and social determinants of behavior. The effect of environmental variability on investment and extraction levels was only observed in specific sequences, i.e., sequences 2 and 3 in Table 1.

Table 1. Treatment designs.

\begin{tabular}{|c|c|c|c|c|c|}
\hline & $\begin{array}{l}\text { Short- } \\
\text { Name }\end{array}$ & $\begin{array}{l}\text { \# of } \\
\text { groups }\end{array}$ & $\begin{array}{c}\text { Treatment } \\
\text { Period 1 } \\
\text { Rounds 1-5 }\end{array}$ & $\begin{array}{c}\text { Treatment } \\
\text { Period } 2 \\
\text { Rounds 6-10 }\end{array}$ & $\begin{array}{c}\text { Treatment } \\
\text { Period } 3 \\
\text { Rounds } \\
11-15\end{array}$ \\
\hline Sequence 1 & $\mathrm{NLH}$ & 6 & $\begin{array}{c}\text { No } \\
\text { Variability }\end{array}$ & $\begin{array}{c}\text { Low } \\
\text { Variability }\end{array}$ & $\begin{array}{c}\text { High } \\
\text { Variability }\end{array}$ \\
\hline Sequence 2 & NHL & 5 & $\begin{array}{c}\text { No } \\
\text { Variability }\end{array}$ & $\begin{array}{c}\text { High } \\
\text { Variability }\end{array}$ & $\begin{array}{c}\text { Low } \\
\text { Variability }\end{array}$ \\
\hline Sequence 3 & LHN & 5 & $\begin{array}{c}\text { Low } \\
\text { Variability }\end{array}$ & $\begin{array}{c}\text { High } \\
\text { Variability }\end{array}$ & $\begin{array}{c}\text { No } \\
\text { Variability }\end{array}$ \\
\hline
\end{tabular}

LHN, low, high, and no variability;

NHL, no, high, and low variability;

NLH, no, low, and high variability.

\section{EXPERIMENT DESIGN}

Each experimental session started with individuals being assigned randomly to a seat in the lab. After seat assignments, we implemented the Holt and Laury (2002) risk elicitation exercise (see Appendix 1) and trust using the Trust Game from Berg et al. (1995); see Appendix 1 for details. The Trust Game used the strategy method of each participant submitting decisions as both the proposer and respondent. The order of the exercises was kept fixed as follows: Risk Elicitation (Aversion), Trust Game, and Irrigation Game. During the Trust Game, participants were made aware that they would be randomly paired with any other participant in the room to assess their performance. When we started the Irrigation Game, we explained that each individual would interact only with the same four other individuals for the duration of the experiment. Pairing was anonymous, and scores stemming from the trust and risk games were calculated only after the Irrigation Game was over, although those games were played before the Irrigation Game. Once all exercises were completed, we collected additional sociodemographic information via an individual survey (reported in Appendix 1).

The main experiment performed was a five-person irrigation game (see Appendix 1 for the detailed instructions given to each participant regarding the experiment). These five participants were randomly allocated to positions A, B, C, D, and E, with A being the furthest upstream participant and $E$ being the furthest downstream participant. The participants kept the same position during the duration of the whole experiment. The experiment mimicked the provision of infrastructure and the distribution of water that small-scale irrigation systems require (Cifdaloz et al. 2010, Janssen et al. 2012). Figure 1 provides a graphical representation of the investment and extraction stages of our Irrigation Game. Appendix 1 provides the exact experimental protocol. 
Fig. 1. Flow chart of one irrigation experiment round.

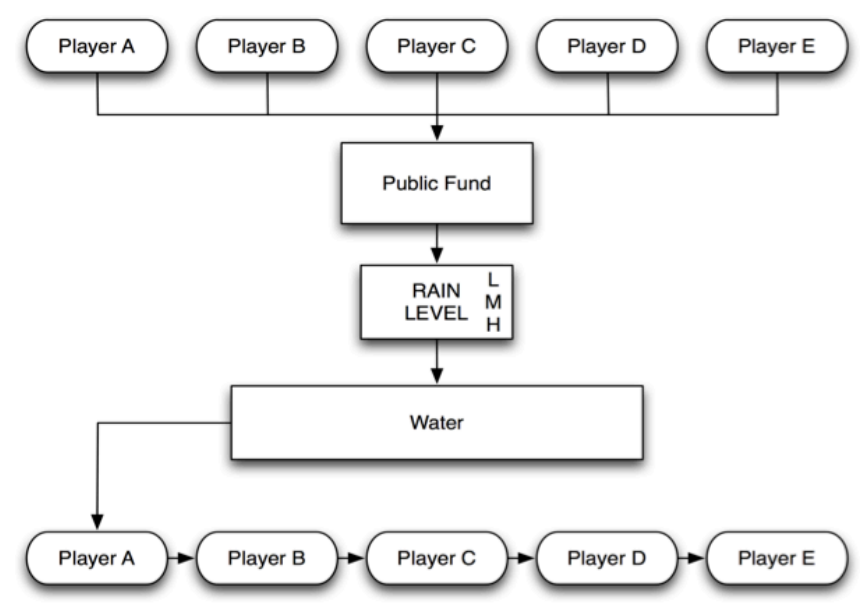

At the beginning of each round, each participant received an endowment of ten tokens, which they could invest into the irrigation infrastructure or keep for themselves. Each token was worth five cents. The total investment of the five participants defined the state of the irrigation system. Table 2 shows the amount of water that could flow through the irrigation system based on the total investment.

Table 2. Water production as a function of units invested in the public infrastructure. The table includes a default production function (medium), as well as a production function during a dry round (low) and an affluent round (high).

\begin{tabular}{lccc}
\hline \hline $\begin{array}{l}\text { Total units invested } \\
\text { by all players }\end{array}$ & $\begin{array}{c}\text { Water available } \\
\text { (low) }\end{array}$ & $\begin{array}{c}\text { Water } \\
\text { available } \\
\text { (medium) }\end{array}$ & $\begin{array}{c}\text { Water } \\
\text { available } \\
\text { (high) }\end{array}$ \\
\hline $0-10$ & 0 & 0 & 0 \\
$11-15$ & 2 & 5 & 8 \\
$16-20$ & 8 & 20 & 32 \\
$21-25$ & 16 & 40 & 64 \\
$26-30$ & 24 & 60 & 96 \\
$31-35$ & 30 & 75 & 120 \\
$36-40$ & 34 & 85 & 136 \\
$41-45$ & 38 & 95 & 152 \\
$46-50$ & 40 & 100 & 160 \\
\hline
\end{tabular}

In the second half of the round, each participant in sequential turns from upstream to downstream (from the player in position A to the player in position E) decided how much water to extract from the available water. Available water was the total water produced by the group minus the water already extracted by the upstream participants. For example, water available for a player in position $\mathrm{C}$ was equal to the total water generated minus the water extracted by the player in position $\mathrm{A}$ and the player in position B. Each individual knew how much water was at his or her disposal and was told at the beginning of each extraction phase how much water was available to the whole group. Knowing the total water availability before the extraction phase allowed each player to infer how much the whole group has invested in the resource. Knowing the total water availability before the extraction phase also allowed group members to know how much was extracted by upstream users. For example, player B could infer how much player A extracted (the amount of water available for the group minus the amount of water available for player B), player $C$ could easily infer the total amount of water extracted by players $\mathrm{A}$ and $\mathrm{B}$ combined, and so on.

Each token kept in the investment stage added to each token extracted in the extraction stage of each round. The number of tokens kept and tokens extracted over all 15 rounds were then calculated to determine the payment made to each participant. The average total payout was $\$ 22.83$ (standard deviation $=\$ 6.20$ ). The average total payout represented average payment based on performance in the Irrigation Game, the earnings from the trust and risk aversion exercises, and a show-up fee of $\$ 5$. Each session lasted for about 1 hour.

Each session consisted of 1 practice round to demonstrate the game's procedures and 15 decision rounds played for money, split into three 5-round treatment periods. Players were not informed of the actual length of the experiment to avoid the "final round" effect. Each of the 3 periods applied different levels of environmental variability. We distinguished between low, medium, and high rainfall rounds, representing dry, standard, and heavy water conditions. The low rainfall condition had $60 \%$ less rainfall than the medium rainfall condition for the same level of investment, and the high rainfall condition had $60 \%$ more rainfall than the medium condition. We also distinguished between 3 levels of environmental variability:

1. No variability (no investment risk). Rainfall level was fixed at the medium level as in Table 2.

2. Low variability (low investment risk). Randomly determined use of the low (1/6 probability), medium (2/3 probability), or high (1/6 probability) columns in Table 2 to elicit water availability.

3. High variability (high investment risk). Randomly determined $1 / 3$ probability for each of the three possible columns in Table 2 to elicit water availability.

We defined three treatments with different sequences of the type of variability in the experiment session (Table 1). The different sequences were chosen to test the effect of different levels of variability while controlling for possible learning effects. We were aware that many more sequences could be designed; however, having a comprehensive experiment in which all possible sequence combinations are tested was not feasible given cost constraints and the availability of test subjects. Individuals could not participate more than once in the same experiment, even in different sessions with different variability sequences. Investment levels in the baseline sequence (no, low, and high variability $[\mathrm{NLH}])$ were significantly different from levels in the other sequences assessed (low, high, and no variability [LHN] and no, high, and low variability [NHL]); however, LHN and NHL did not display any statistically significant difference.

According to Rational Choice Theory, the expected behavior for all players was to invest zero tokens each round. This is because investing zero tokens is the Nash equilibrium. If we assume people act out of rational self-interest, participants in positions $\mathrm{B}$ to $\mathrm{E}$ 
Table 3. Definition and summary statistics for the variables used in the statistical model. Variables are defined in the main text. For categorical variables, the percentage of values in a specific category is reported in the mean column jointly with the general mean value. Avg refers to group averages per round. Gini coefficients were calculated over a specific group and varied at each round.

\begin{tabular}{|c|c|c|c|c|c|c|}
\hline Variable & $\mathrm{N}$ & Mean & SD & Median & Min & Max \\
\hline Investment & 1200 & 5.87 & 3.46 & 6.00 & 0.00 & 10.00 \\
\hline Avg Investment & 1200 & 5.87 & 1.98 & 5.80 & 0.20 & 10.00 \\
\hline Extraction & 1200 & 11.83 & 12.08 & 10.00 & 0.00 & 76.00 \\
\hline Avg Extraction & 1200 & 11.83 & 7.37 & 12.00 & 0.00 & 32.00 \\
\hline Trust & 1200 & 0.65 & 0.31 & 0.67 & 0.00 & 1.00 \\
\hline Avg Trust & 1200 & 0.65 & 0.05 & 0.63 & 0.62 & 0.74 \\
\hline Trustworthiness & 1200 & 0.40 & 0.16 & 0.44 & 0.00 & 0.67 \\
\hline Avg Trustworthiness & 1200 & 0.40 & 0.08 & 0.40 & 0.18 & 0.49 \\
\hline Normalized Risk Scores & 1200 & 0.53 & 0.14 & 0.50 & 0.20 & 0.90 \\
\hline Avg Normalized Risk Scores & 1200 & 0.53 & 0.02 & 0.53 & 0.50 & 0.55 \\
\hline Equal Share Ratio & 1150 & 1.00 & 0.95 & 0.99 & 0.00 & 5.00 \\
\hline Net Gain & 1200 & 10.09 & 11.34 & 10.00 & -10.00 & 75.00 \\
\hline Extraction Gini Coefficient & 1200 & 0.36 & 0.24 & 0.32 & 0.00 & 0.80 \\
\hline Investment Gini Coefficient & 1200 & 0.39 & 0.19 & 0.25 & 0.00 & 0.80 \\
\hline Treatment & 1200 & 0.625 & 0.484 & 1.00 & 0.00 & 1.00 \\
\hline NLH $(\%)$ & 450 & 37.50 & & & & \\
\hline NHL or LHN $(\%)$ & 700 & 62.50 & & & & \\
\hline Variability & 1200 & 1.00 & 0.82 & 1.00 & 0.00 & 2.00 \\
\hline None $(\%)$ & 400 & 33.33 & & & & \\
\hline Low $(\%)$ & 400 & 33.33 & & & & \\
\hline High $(\%)$ & 400 & 33.33 & & & & \\
\hline Treatment*Variability & 1200 & 2.88 & 1.67 & 3.00 & 0.00 & 5.00 \\
\hline NLH * No Variability $(\%)$ & 150 & 12.50 & & & & \\
\hline NLH * Low Variability & 150 & 12.50 & & & & \\
\hline NLH ${ }^{*}$ High Variability & 150 & 12.50 & & & & \\
\hline NHLorLHN * No Variability & 250 & 20.83 & & & & \\
\hline NHLorLHN * Low Variability & 250 & 20.83 & & & & \\
\hline NHLorLHN * High Variability & 250 & 20.83 & & & & \\
\hline Rainfall & 1200 & 1.04 & 0.63 & 1.00 & 0.00 & 2.00 \\
\hline Low $(\%)$ & 215 & 17.92 & & & & \\
\hline Medium $(\%)$ & 720 & 60.00 & & & & \\
\hline High $(\%)$ & 265 & 22.08 & & & & \\
\hline Position & 1200 & 3.00 & 1.41 & 3.00 & 1.00 & 5.00 \\
\hline $\mathrm{A}(\%)$ & 240 & 20.00 & & & & \\
\hline B $(\%)$ & 240 & 20.00 & & & & \\
\hline $\mathrm{C}(\%)$ & 240 & 20.00 & & & & \\
\hline $\mathrm{D}(\%)$ & 240 & 20.00 & & & & \\
\hline E $(\%)$ & 240 & 20.00 & & & & \\
\hline
\end{tabular}

LHN, low, high, and no variability;

NHL, no, high, and low variability;

NLH, no, low, and high variability.

would expect player A to take all the water and therefore would not invest. Because a single person investing in the common infrastructure would not increase the amount of water available in the second stage, participant A also would not invest. Therefore, the Nash equilibrium would always be zero investment, independent of the level of variability, and thus zero extractions because no water was generated. However, people do not generally act solely out of rational self-interest. Instead, especially in repeated games, they are observed to act based on other preferences, such as trust and observable group behavior (Ostrom 1998).

\section{DATA DESCRIPTION}

Data used in this analysis were derived from six sessions of experiments performed during the spring of 2012 with undergraduate students at Arizona State University. The data set consists of 16 groups of 5 individuals who recorded their decisions for 15 rounds, resulting in 1200 observations. Summary statistics for the variables used are reported in Table 3.

Investment refers to the amount invested in the public infrastructure, generating the common water resource. Investment is, for all intents and purposes, a proxy for collective action (Beckenkamp et al. 2007, Janssen et al. 2011) and is our main variable of interest, i.e., the dependent variable. Extraction refers to the amount extracted once water was generated. Trust and trustworthiness were measured by normalized scores representing the amount of money sent to another participant (trust) or sent back (trustworthiness) in the Trust Game (see Appendix 1 for details); the higher the score, the more trusting and/or trustworthy an individual is. Both trust and trustworthiness were normalized by dividing the actual money sent or sent back by the maximum amount that it was possible to 
send or send back. Trust and trustworthiness are deemed to be important determinants for collective action (Ostrom 1998). Risk score was the normalized score of the number of low-risk choices in the Risk Aversion Game; thus, the higher the score, the more risk averse an individual was (see Appendix 1 for details). Risk scores were normalized by counting the number of low-risk choices divided by the maximum number of low-risk choices available. Normalized risk scores are considered inversely related to cooperation if others' behavior is unknown a priori. Variability refers to high, low, or no variability in water generation. In other words, variability refers to the probability of using the left, the middle, or the right column of Table 2. Sequence refers to the different order in which variability levels were communicated to the participants. For example, in sequence NLH, the first five rounds were played with no variability, the next five rounds were played with low variability, and finally five rounds were played with high variability. In sequence LHN, the first five rounds were played with low variability, then five rounds with high variability, and finally five rounds with no variability. Rainfall refers to the actual amount of water generated in a round. Position refers to the position in which an individual will extract resources (position A being the first to make a choice and position E the last).

***The ESR for person $i$ at round $t\left(E S R_{i, t}\right)$ was calculated as the actual amount extracted by individual $i$ at round $t\left(E_{i, \mathrm{t}}\right)$ divided by the total water available to the group at round $t$ at the beginning of the extraction phase $\left(R_{t}\right)$ divided by 5 (i.e., the amount to extract that would allow everyone in the group to extract an equal amount of the resource at time $t$ ):

$$
E S R_{i, t}=E_{i, t} /\left(R_{t} / 5\right)
$$

If the ESR was less than 1, individual $i$ extracted less than an equitable share, whereas an ESR greater than 1 means that an individual extracted more than an equitable share. An ESR of 1 means that an individual extracted the equitable share. ESR is a simple heuristic measure of how an individual values equality in distribution of resources. An ESR less than 1 might decrease cooperation (i.e., investment) in the subsequent round.

Net gain represents the net profit and is given by:

$$
N G_{i, t}=10-\operatorname{In} v_{i, t}+E x t_{i, t}
$$

The net gain is thus the participant net profit, calculated by the amount extracted plus the number of tokens not invested in the resource.

To assess the effect of variability sequence on investment and extraction, we performed an $\mathrm{X}^{2}$ test. We found that the variability sequence (see Table 1) affected investment and extraction only in comparison with the NLH order $(\mathrm{p}<0.001)$. We did not find any significant difference between treatments LHN and NHL $(p>$ $0.05)$. Given the $X^{2}$ test results, we opted to merge the sequences not leading to significantly different results and include the new sequence dummy variable in our models (value 0 if sequence $=$ NLH and value 1 if sequence $=$ LHN or NHL). We interacted the sequence dummy with environmental variability, and this allowed us to assess the effect of variability on investment and extraction levels. Furthermore, we also hypothesized that the significant difference in variability could be at least partly ascribed to unobserved effects relating to the composition of participants in each session. Future work will concentrate on finding the reason for such differences by analyzing survey data collected during the experiments.

Three patterns clearly emerged from investment/extraction behavior. First, upstream participants invested more than downstream participants (Fig. 2) and, downstream participants extracted less than upstream participants (Fig. 3). On average, within a specific group there was a high level of persistence in the investment and extraction levels (as shown in Fig. S1 and Fig. S2 in Appendix 1). Third, trust appears to have played a role during the first round of the experiment (Fig. 4A), where increased trust led to greater investments in the resource, but this effect seems to have vanished in subsequent rounds (Fig. 4B). Risk aversion played an ambiguous role in affecting investment. More riskneutral participants (normalized risk scores of $0.4,0.5$, and 0.6 ) invested less in the resource. This result can be partially explained by the distribution of individual choices. Intermediate levels were by far the most common choice (61 out of 80 participants had a risk score between 0.4 and 0.6 ) compared with the extremes (1 person had an extremely high risk score, 1 person had an extremely low risk score, 7 participants had scores $<0.4$, and 12 participants had scores $>0.6$; see Fig. 5). Finally, position has a greater impact on the levels of investment and, most of all, on how much individuals extracted from the commonly generated resource (Fig. 6). These preliminary findings seem to indicate the existence of feedbacks between investment, extractions, upstream users' behavior, and trust. This feedback is also described extensively, albeit theoretically, by Ostrom (1998).

\section{DATA ANALYSIS}

To assess how environmental variability, personal characteristics, and upstream users' behavior impacted investments, we regressed individual and group investments on a set of independent

Fig. 2. Tokens invested per sequence and variability level. LHN, low, high, and no variability; NHL, no, high, and low variability; NLH, no, low, and high variability.

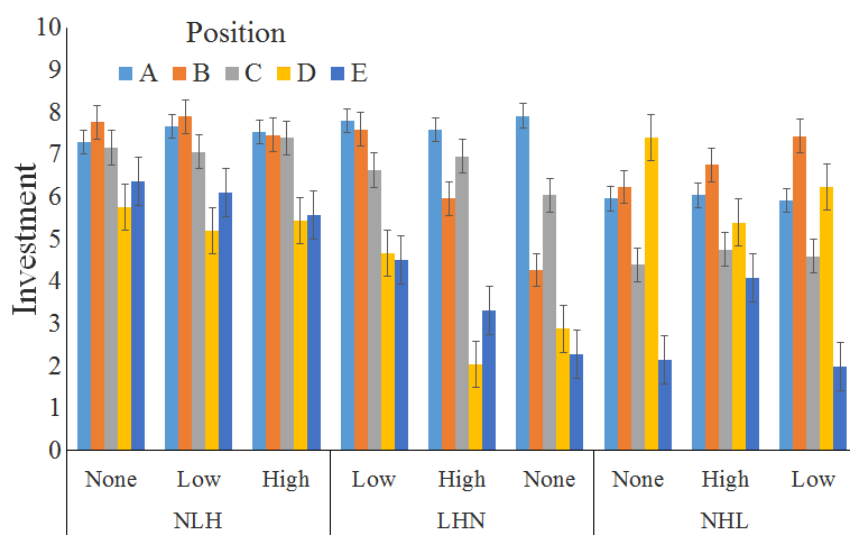

Sequence and Environmental Variability 
Fig. 3. Tokens extracted as fraction of water availability per sequence and variability level. LHN, low, high, and no variability; NHL, no, high, and low variability; NLH, no, low, and high variability.

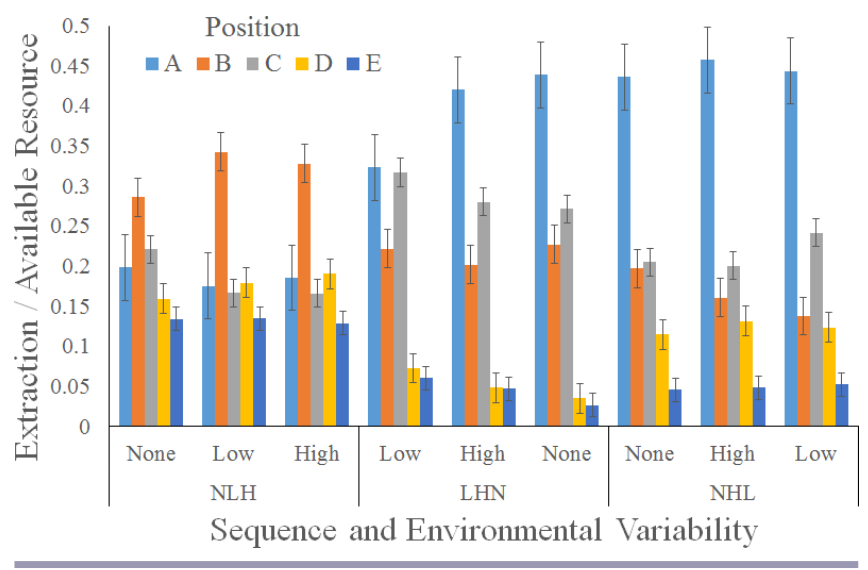

Fig. 4. Average tokens invested depending on trust (thin bars represent standard error).
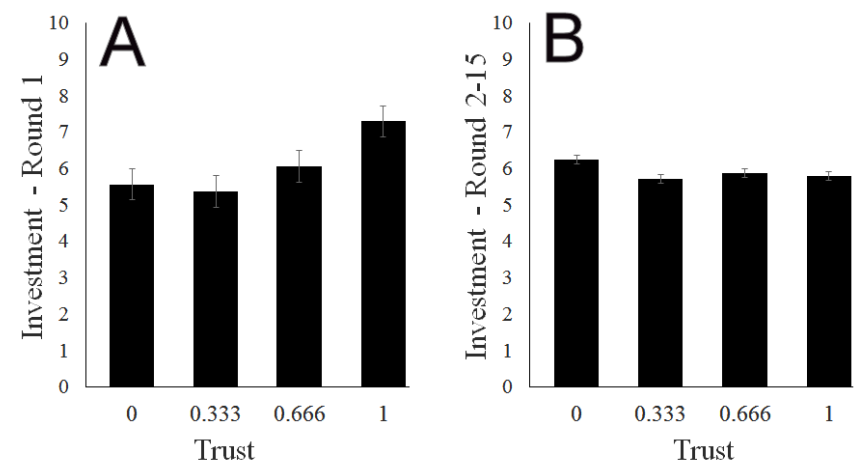

Fig. 5. Average tokens invested depending on normalized risk score. Red line $=$ Frequency of participants making specific choices risk choices (thin bars represent standard error).

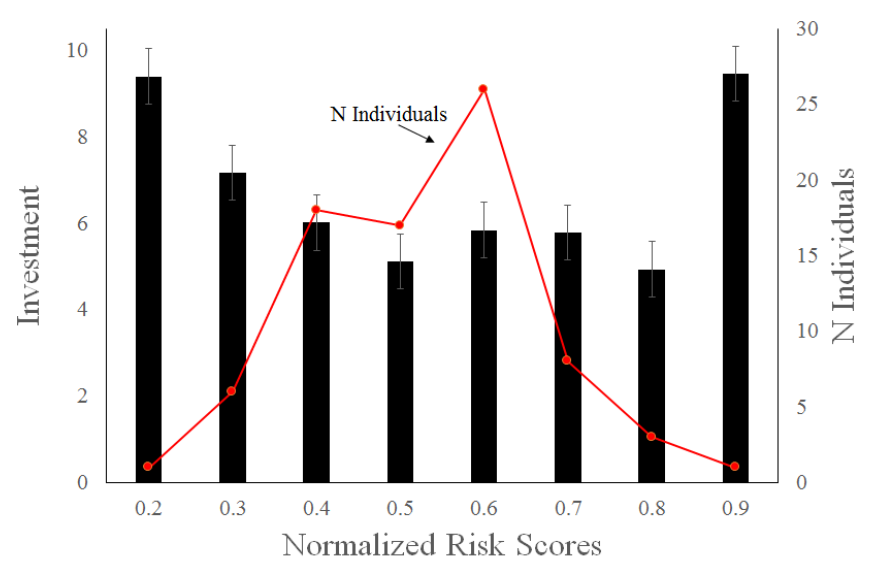

Fig. 6. Average tokens invested and extracted depending on position (thin bars represent standard error).

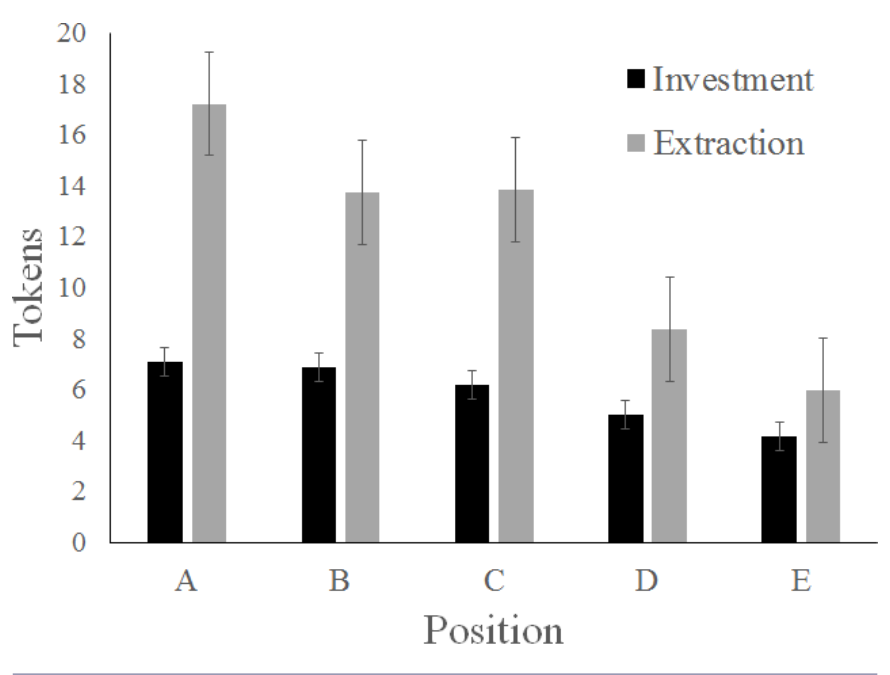

variables, using a hierarchical model with cluster bootstrapped standard errors. Equation 3 and equation 4 formally represent the statistical models devised to assess investment levels.

$$
\begin{aligned}
& I n v_{i, t}=b_{0}+\overrightarrow{b x_{1} D_{S C h a r_{i}}}+\overrightarrow{b x_{2} \text { SChar }_{i}}+b x_{3} S U u b_{i, t-1}+\varepsilon_{i, t} \\
& G r I n v_{i, t}=b_{0}+\overrightarrow{b x_{1} \text { DGrChar }_{i}}+\overrightarrow{b x_{2} \operatorname{GrChar}_{i}}+b x_{3} G r U u b_{i, t-1}+\varepsilon_{i, t}
\end{aligned}
$$

Equation 3 analyzes how individual investment levels (Inv) are dependent upon environmental characteristics, personal characteristics, and upstream users' behavior. Environmental characteristics are composed of position and sequence-variability interactions and are represented by the vector DSChar in equation 3. Personal characteristics are composed of trust, normalized risk scores, and sex, and are represented by the vector SChar in equation 3 . Upstream users' behavior was assessed via the ESR (equation 1) and net gain (equation 2), and is represented by $(U u b)$ in equation 3 . Finally, $\varepsilon_{i, t}$ represents the error term.

Equation 4 is the model we devised to assess group level investment $(G r I n v)$. In this case, we assumed that group-level investment is dependent on the interaction between sequence and variability (DGrChar); average group characteristics (average trust and normalized risk aversion scores) (GrChar); and the effect from observed upstream users' behavior $(\mathrm{Gr} U u b)$ represented by the extraction gini coefficient at $t-1$. $\varepsilon_{i, t}$ is, once again, the error term.

\section{RESULTS AND DISCUSSION}

Tables 4 and 5 report the individual- and group-level results for the models in equations 3 and 4 . To account for initial behavioral effects from trust and risk aversion being attenuated after the first round as participants responded to the actions of the other participants, we modeled the round 1 effects separate from rounds 2-15.

For the individual-level results (Table 4), trust and risk aversion significantly affected the investment levels only in round 1 . From round 2 to round 15, the upstream users' behavior and extraction inequality took a prominent role in explaining the investment level. 
Table 4. Results for the individual-level hierarchical model with standardized coefficients.

\begin{tabular}{|c|c|c|c|c|c|}
\hline & Model 1 & Model 2 & Model 3 & Model 4 & Model 5 \\
\hline & Round1 & \multicolumn{4}{|c|}{ Rounds 2-15 } \\
\hline Round & & $\begin{array}{c}-0.111^{* *} \\
(0.037)\end{array}$ & $\begin{array}{l}-0.059 \\
(0.041)\end{array}$ & $\begin{array}{l}-0.104^{*} \\
(0.035)\end{array}$ & $\begin{array}{l}-0.064 \\
(0.044)\end{array}$ \\
\hline NLH x LowVar & & $\begin{array}{l}0.034^{* *} \\
(0.126)\end{array}$ & $\begin{array}{l}0.014^{*} \\
(0.069)\end{array}$ & $\begin{array}{c}0.032^{* *} \\
(0.116)\end{array}$ & $\begin{array}{l}0.015^{*} \\
(0.070)\end{array}$ \\
\hline NLH x HighVar & & $\begin{array}{c}0.070 \\
(0.592)\end{array}$ & $\begin{array}{c}0.029 \\
(0.411)\end{array}$ & $\begin{array}{c}0.066 \\
(0.575)\end{array}$ & $\begin{array}{l}0.031 \\
(0.413)\end{array}$ \\
\hline LHNorNHL x NoVar & $\begin{array}{c}-0.317^{* *} \\
(0.568)\end{array}$ & $\begin{array}{c}-0.163^{* *} \\
(0.454)\end{array}$ & $\begin{array}{c}-0.191^{* * *} * \\
(0.273)\end{array}$ & $\begin{array}{c}-0.157^{* *} \\
(0.471)\end{array}$ & $\begin{array}{c}-0.195 * * * \\
(0.293)\end{array}$ \\
\hline LHNorNHL x LowVar & $\begin{array}{l}-0.061 \\
(1.176)\end{array}$ & $\begin{array}{c}-0.082+ \\
(0.369)\end{array}$ & $\begin{array}{l}-0.063 \\
(0.468)\end{array}$ & $\begin{array}{l}-0.081^{*} \\
(0.336)\end{array}$ & $\begin{array}{l}-0.064 \\
(0.497)\end{array}$ \\
\hline LHNorNHL x HighVar & & $\begin{array}{l}-0.135^{*} \\
(0.508)\end{array}$ & $\begin{array}{c}-0.151^{* *} \\
(0.477)\end{array}$ & $\begin{array}{l}-0.137^{*} \\
(0.484)\end{array}$ & $\begin{array}{c}-0.149^{*} \\
(0.489)\end{array}$ \\
\hline Position B & $\begin{array}{c}0.012 \\
(0.699)\end{array}$ & $\begin{array}{l}-0.046 \\
(0.444)\end{array}$ & $\begin{array}{l}-0.051 \\
(0.738)\end{array}$ & $\begin{array}{l}-0.040 \\
(0.537)\end{array}$ & $\begin{array}{l}-0.050 \\
(0.741)\end{array}$ \\
\hline Position C & $\begin{array}{c}-0.074+ \\
(0.272)\end{array}$ & $\begin{array}{c}-0.114+ \\
(0.591)\end{array}$ & $\begin{array}{l}-0.097 \\
(0.727)\end{array}$ & $\begin{array}{l}-0.110 \\
(0.683)\end{array}$ & $\begin{array}{l}-0.095 \\
(0.738)\end{array}$ \\
\hline Position D & $\begin{array}{l}-0.096 \\
(0.654)\end{array}$ & $\begin{array}{c}-0.266^{* * * *} \\
(0.664)\end{array}$ & $\begin{array}{l}-0.226^{*} \\
(0.806)\end{array}$ & $\begin{array}{c}-0.251 * * \\
(0.709)\end{array}$ & $\begin{array}{c}-0.225^{*} \\
(0.813)\end{array}$ \\
\hline Position E & $\begin{array}{c}-0.335^{* *} \\
(0.778)\end{array}$ & $\begin{array}{c}-0.359 * * * \\
(0.553)\end{array}$ & $\begin{array}{c}-0.316^{* * * *} \\
(0.571)\end{array}$ & $\begin{array}{c}-0.342 * * * \\
(0.562)\end{array}$ & $\begin{array}{c}-0.314 * * * \\
(0.572)\end{array}$ \\
\hline Normalized Risk Scores & $\begin{array}{l}0.170^{*} \\
(1.533)\end{array}$ & $\begin{array}{l}-0.022 \\
(1.044)\end{array}$ & $\begin{array}{l}-0.026 \\
(1.333)\end{array}$ & $\begin{array}{l}-0.022 \\
(1.229)\end{array}$ & $\begin{array}{c}-0.028 \\
(1.303)\end{array}$ \\
\hline Trust & $\begin{array}{c}0.326^{* * *} \\
(0.333)\end{array}$ & $\begin{array}{c}0.009 \\
(0.753)\end{array}$ & $\begin{array}{c}0.042 \\
(0.594)\end{array}$ & $\begin{array}{c}0.017 \\
(0.710)\end{array}$ & $\begin{array}{c}0.039 \\
(0.603)\end{array}$ \\
\hline Sex & $\begin{array}{l}-0.027 \\
(0.551)\end{array}$ & $\begin{array}{c}-0.142 * * \\
(0.317)\end{array}$ & $\begin{array}{c}-0.154 * * * \\
(0.249)\end{array}$ & $\begin{array}{c}-0.141^{* *} \\
(0.318)\end{array}$ & $\begin{array}{c}-0.155^{* * *} \\
(0.265)\end{array}$ \\
\hline $\operatorname{ESR}(\mathrm{t}-1)$ & & & $\begin{array}{l}0.144^{*} \\
(0.236)\end{array}$ & & $\begin{array}{c}0.176^{* *} \\
(0.201)\end{array}$ \\
\hline NetGain (t-1) & & & & $\begin{array}{c}0.063 \\
(0.016)\end{array}$ & $\begin{array}{c}-0.049^{*} \\
(0.007)\end{array}$ \\
\hline $\mathrm{N}$ & 80.000 & 1120.000 & 1075.000 & 1120.000 & 1075.000 \\
\hline $\mathrm{AIC}$ & 377.694 & 5723.548 & 5430.848 & 5718.632 & 5429.021 \\
\hline
\end{tabular}

Note: $+=$ significant at the $90 \%$ level, $*=$ significant at the $95 \%$ level, $* *=$ significant at the $99 \%$ level, and $* * *=$ significant at the $99.9 \%$ level. Cluster bootstrapped standard errors are in parentheses; group is the cluster variable. Position was compared with position A. Sequence and Variability were compared with Sequence NLH and No Variability. $(\mathrm{t}-1)$ indicates the use of a lagged variable. LHN, low, high, and no variability; NHL, no, high, and low variability; NLH, no, low, and high variability.

For the group results, however, the average trust and risk aversion scores significantly affected investments even after the first round (Table 5).

Although it was not possible to assess the full interaction between extraction and investment decisions using the models in equations 3 and 4 , the effect of upstream users' behavior in determining subsequent investments is clear. At the individual level, position and upstream users' behavior, measured here simply by ESR and net gain, had a significant effect on the level of investment, which is also confirmed by the group-level gini coefficient: increased inequality reduced investments. Net gain seemed to actually lower investments, and by consequence, extractions. ESR had a positive and significant effect on investments: the higher the ESR, the more a person was willing to invest, and consequently extraction might be higher. These results need to be contextualized within the experiment, in which some individuals were in privileged positions although still dependent on others' contributions and in which actions of upstream users could be, on average, known to downstream users.
In the first round, there was no prior behavior for participants to respond to. Therefore, during the first round, individual-level characteristics, e.g., trust and risk aversion, were hypothesized to be the main drivers influencing investment independently from other factors such as observed upstream users' behavior, confirming results from field experiments (Janssen et al. 2012). Position has a smaller effect on investment, because only positions $\mathrm{C}$ and $\mathrm{E}$ extracted significantly less than position $\mathrm{A}$. On the other hand, trust significantly increased the investment. The interplay between trust, investment, and extraction in the first round set in motion the behavior for the subsequent rounds (see also Tables 6 and 7). After the first round, trust did not appear to have a clear effect or significance, and positions $\mathrm{D}$ and $\mathrm{E}$ invested significantly less and almost always extracted significantly less than position A. Positions B and C on average invested the same amount (i.e., there was no significant difference in investment between positions $\mathrm{B}$ and $\mathrm{C}$; Wald $\mathrm{p}>0.1$ ), whereas position $\mathrm{E}$ on average invested a significantly different amount than position D (Wald $\mathrm{p}<0.001)$. These results hold for all models presented in Table 4. In other words, whereas the central positions (B and C) seemed 
Table 5. Results for the group-level model with standardized coefficients.

\begin{tabular}{|c|c|c|c|c|c|}
\hline & Model 1 & Model 2 & Model 3 & Model 4 & Model 5 \\
\hline & Round 1 & \multicolumn{4}{|c|}{ Rounds 2-15 } \\
\hline Round & & $\begin{array}{c}-0.213^{* * *} \\
(0.015)\end{array}$ & $\begin{array}{c}-0.211^{* * *} \\
(0.016)\end{array}$ & $\begin{array}{c}-0.212^{* * *} \\
(0.016)\end{array}$ & $\begin{array}{c}-0.193^{* * *} \\
(0.015)\end{array}$ \\
\hline NLH x LowVar & $\begin{array}{l}-0.015 \\
(0.178)\end{array}$ & $\begin{array}{c}0.044 \\
(0.162)\end{array}$ & $\begin{array}{c}0.045 \\
(0.215)\end{array}$ & $\begin{array}{c}0.044 \\
(0.212)\end{array}$ & $\begin{array}{l}0.058+ \\
(0.188)\end{array}$ \\
\hline NLH x HighVar & $\begin{array}{l}-0.033 \\
(0.181)\end{array}$ & $\begin{array}{c}0.111^{* * *} \\
(0.197)\end{array}$ & $\begin{array}{c}0.112^{* *} \\
(0.242)\end{array}$ & $\begin{array}{c}0.111^{* *} \\
(0.235)\end{array}$ & $\begin{array}{c}0.122^{* *} \\
(0.224)\end{array}$ \\
\hline LHNorNHL x NoVar & $\begin{array}{c}-0.638^{* * *} \\
(0.225)\end{array}$ & $\begin{array}{c}-0.186^{* * *} \\
(0.152)\end{array}$ & $\begin{array}{c}-0.211^{* * * *} \\
(0.187)\end{array}$ & $\begin{array}{c}-0.195^{* * *} \\
(0.184)\end{array}$ & $\begin{array}{c}-0.274^{* * * *} \\
(0.178)\end{array}$ \\
\hline LHNorNHL x LowVar & $\begin{array}{l}-0.068 \\
(0.332)\end{array}$ & $\begin{array}{c}-0.097^{* *} \\
(0.155)\end{array}$ & $\begin{array}{c}-0.118^{* *} \\
(0.194)\end{array}$ & $\begin{array}{c}-0.105^{* *} \\
(0.189)\end{array}$ & $\begin{array}{c}-0.132^{* * *} \\
(0.165)\end{array}$ \\
\hline LHNorNHL x HighVar & & $\begin{array}{c}-0.134 * * * \\
(0.164)\end{array}$ & $\begin{array}{c}-0.161 * * * \\
(0.200)\end{array}$ & $\begin{array}{c}-0.144 * * * \\
(0.192)\end{array}$ & $\begin{array}{c}-0.225^{* * *} * \\
(0.188)\end{array}$ \\
\hline Gini Extraction $\left(t_{-1}\right)$ & & $\begin{array}{c}-0.335^{* * *} \\
(0.240)\end{array}$ & $\begin{array}{c}-0.308^{* * *} \\
(0.259)\end{array}$ & $\begin{array}{c}-0.327^{* * *} \\
(0.265)\end{array}$ & \\
\hline avg Trust & $\begin{array}{c}0.055 \\
(2.850)\end{array}$ & $\begin{array}{c}0.089^{* * *} * \\
(0.716)\end{array}$ & & $\begin{array}{c}0.097 * * * \\
(0.816)\end{array}$ & $\begin{array}{c}0.031 \\
(0.884)\end{array}$ \\
\hline avg Normalized Risk Scores & $\begin{array}{l}-0.067 \\
(4.844)\end{array}$ & $\begin{array}{c}0.398 * * * \\
(2.675)\end{array}$ & & & $\begin{array}{c}0.392 * * * \\
(2.732)\end{array}$ \\
\hline $\mathrm{N}$ & 80.000 & 1120.000 & 1120.000 & 1120.000 & 1120.000 \\
\hline AIC & 223.393 & 4164.662 & 4442.871 & 4431.514 & 4336.142 \\
\hline
\end{tabular}

to invest on average the same amount, there were differences within the tail-end positions ( $\mathrm{D}$ and $\mathrm{E}$ ). The comparison between the first round and subsequent rounds appears to reinforce the importance of the feedback between trust, observable actions, and collective action, as described by Ostrom (1998).

Similarly to trust, risk aversion was significant only in the first round (Table 4). This is another indication of the importance of personal characteristics in one-shot games and at the beginning of a "collective action enterprise." However, the fact that risk aversion and trust were not significant in subsequent rounds points to the fact that personal characteristic effects become, at least statistically, nonsignificant in the face of general group behavior, i.e., upstream users' behavior.

Finally, during the first round, variability did not appear to be significant. However, the significant effect of LHNorNHL $\mathrm{x}$ NoVar seems to indicate that decisions in round 1 differed because of unmeasured effects pertaining to group composition in the different sequences explored. On the other hand, in the models representing rounds 2-15 (Table 4), high environmental variability seemed to contribute to reduced investments, compared with the baseline scenario of no variability and the NLH sequence. High variability, when the variability sequence was LHNorNHL, had a significant impact on investments, and this may have led, indirectly, to reduced extractions. The significant effect of high variability was also confirmed by the fact that LHNorNHL $x$ HighVar was significantly different than LHNorNHL $x$ NoVar and LHNorNHL x LowVar ( $p<0.05$ in both cases). The test results hold true for all specifications presented in Table 4. This finding is in line with previous findings on the effect of environmental variability on collective action (Walker and Gardner 1992, Biel and Gärling 1995, Anderies et al. 2013).
The description of the results holds at the group level (Table 5) with some interesting differences. Although upstream users, behavior is always an important factor determining the level of group investment, average group risk scores and average trust are not significant within the first round but become mostly significant in subsequent rounds. The effect of averaged group risk and trust scores is different than the individual trust and risk effect. Group propensity for risk and trust seem to be important at the aggregate level, but their effect is dampened at the individual level.

The use of standardized coefficients, i.e., betas, allowed us to compare the effects of the different variables on investment at the group and individual levels. We started by analyzing the magnitude of the significant coefficients for the individual-level models (Table 4$)$. In round 1 , (model 1$)$, trust was the most important factor positively affecting investment, whereas being positioned at the tail end of the group was, from the beginning of the game, the most important factor negatively affecting investment. The results of the first round of the experiment confirm the importance of trust in affecting collective action, especially in one-shot games (Biel and Garling 1995). Being positioned at the tail end had a definite effect on extraction expectation, which sensibly lowered investment into the commonpool resource for individuals occupying these positions. This latter result is also in line with previous experimental studies (Janssen et al. 2012, Cardenas et al. 2013). In rounds 2-15, the role of trust was supplanted by ESR, which took on an important role in positively affecting investment levels. Meanwhile, positioning was still the most important factor negatively impacting collective action. Once again, the results of our individual-level models are in line with previous literature, in 
Table 6. Results for the model reported in equation 5 with standardized coefficients.

\begin{tabular}{|c|c|c|c|c|}
\hline \multirow[t]{2}{*}{$\begin{array}{l}\text { Dep } \\
\text { Variables } \\
\text { Indep Variables }\end{array}$} & $\mathrm{R} 1$ & NG & ESR & ALL \\
\hline & Round 1 & \multicolumn{3}{|c|}{ Rounds 2-15 } \\
\hline \multicolumn{5}{|l|}{ INV } \\
\hline Position B & $\begin{array}{c}0.053 \\
(0.136)\end{array}$ & $\begin{array}{l}-0.012 \\
(0.034)\end{array}$ & $\begin{array}{c}-0.054 * * * \\
(0.033)\end{array}$ & $\begin{array}{l}-0.014 \\
(0.031)\end{array}$ \\
\hline Position $\mathrm{C}$ & $\begin{array}{c}-0.047 \\
(0.139)\end{array}$ & $\begin{array}{l}-0.005 \\
(0.036)\end{array}$ & $\begin{array}{c}-0.064 * * * \\
(0.037)\end{array}$ & $\begin{array}{l}-0.007 \\
(0.033)\end{array}$ \\
\hline Position D & $\begin{array}{c}-0.017 \\
(0.184)\end{array}$ & $\begin{array}{c}-0.055^{* * *} \\
(0.039)\end{array}$ & $\begin{array}{c}-0.186^{* * *} \\
(0.038)\end{array}$ & $\begin{array}{c}-0.060 * * * \\
(0.036)\end{array}$ \\
\hline Position E & $\begin{array}{c}-0.268^{* * *} \\
(0.145)\end{array}$ & $\begin{array}{c}-0.086^{* * *} \\
(0.044)\end{array}$ & $\begin{array}{c}-0.271 * * * \\
(0.045)\end{array}$ & $\begin{array}{c}-0.088^{* * *} \\
(0.044)\end{array}$ \\
\hline NLH x LowVar & & $\begin{array}{l}-0.013 \\
(0.064)\end{array}$ & $\begin{array}{c}0.018 \\
(0.052)\end{array}$ & $\begin{array}{c}0.004 \\
(0.061)\end{array}$ \\
\hline NLH x HighVar & & $\begin{array}{c}0.042 \\
(0.074)\end{array}$ & $\begin{array}{l}0.048^{*} \\
(0.063)\end{array}$ & $\begin{array}{c}0.042 \\
(0.071)\end{array}$ \\
\hline LHNorNHL x NoVar & $\begin{array}{c}-0.338 * * * \\
(0.096)\end{array}$ & $\begin{array}{c}-0.067 * * \\
(0.066)\end{array}$ & $\begin{array}{c}-0.184 * * * \\
(0.057)\end{array}$ & $\begin{array}{c}-0.054^{*} \\
(0.065)\end{array}$ \\
\hline LHNorNHL x LowVar & $\begin{array}{l}-0.058 \\
(0.111)\end{array}$ & $\begin{array}{c}-0.077 * * \\
(0.065)\end{array}$ & $\begin{array}{c}-0.113^{* * *} \\
(0.057)\end{array}$ & $\begin{array}{l}-0.048^{*} \\
(0.062)\end{array}$ \\
\hline LHNorNHL x HighVar & & $\begin{array}{c}-0.087 * * * \\
(0.057)\end{array}$ & $\begin{array}{c}-0.215^{* * *} \\
(0.052)\end{array}$ & $\begin{array}{c}-0.077 * * \\
(0.055)\end{array}$ \\
\hline Normalized Risk Scores & $\begin{array}{c}0.102 * * \\
(0.206)\end{array}$ & $\begin{array}{c}0.007 \\
(0.105)\end{array}$ & $\begin{array}{c}0.025 \\
(0.093)\end{array}$ & $\begin{array}{l}-0.007 \\
(0.097)\end{array}$ \\
\hline Trust & $\begin{array}{c}0.378 * * * \\
(0.077)\end{array}$ & $\begin{array}{l}-0.010 \\
(0.041)\end{array}$ & $\begin{array}{c}0.036 * * \\
(0.040)\end{array}$ & $\begin{array}{l}-0.006 \\
(0.039)\end{array}$ \\
\hline UUB NG & & $\begin{array}{c}2.333 * * \\
(0.078)\end{array}$ & & $\begin{array}{c}2.501 \\
(5.330)\end{array}$ \\
\hline UUB ESR & & & $\begin{array}{c}-0.166^{* * *} \\
(0.051)\end{array}$ & $\begin{array}{c}0.036 \\
(0.326)\end{array}$ \\
\hline Extraction $(\mathrm{t}-1)$ & & $\begin{array}{c}2.584 * * * \\
(0.046)\end{array}$ & $\begin{array}{c}0.371^{* * *} \\
(0.020)\end{array}$ & $\begin{array}{c}2.667 * * * \\
(0.055)\end{array}$ \\
\hline Round & & $\begin{array}{c}-0.066^{* *} * \\
(0.006)\end{array}$ & $\begin{array}{c}-0.100 * * * \\
(0.006)\end{array}$ & $\begin{array}{c}-0.064 * * \\
(0.005)\end{array}$ \\
\hline Constant & $\begin{array}{c}-0.560 * * \\
(0.152)\end{array}$ & $\begin{array}{c}0.330^{* * *} \\
(0.089)\end{array}$ & $\begin{array}{c}0.641 * * * \\
(0.082)\end{array}$ & $\begin{array}{c}0.352 * * * \\
(0.080)\end{array}$ \\
\hline \multicolumn{5}{|l|}{ EXT } \\
\hline Investment & $\begin{array}{c}-0.556^{* * *} \\
(0.174)\end{array}$ & $\begin{array}{c}0.258 * * * \\
(0.021)\end{array}$ & $\begin{array}{c}0.760 * * * \\
(0.085)\end{array}$ & $\begin{array}{c}0.116^{* * *} \\
(0.021)\end{array}$ \\
\hline Position B & $\begin{array}{l}-0.048 \\
(0.192)\end{array}$ & $\begin{array}{c}-0.075 * * * \\
(0.040)\end{array}$ & $\begin{array}{c}0.035 \\
(0.046)\end{array}$ & $\begin{array}{l}-0.015 \\
(0.036)\end{array}$ \\
\hline Position C & $\begin{array}{l}-0.035 \\
(0.139)\end{array}$ & $\begin{array}{l}-0.046^{*} \\
(0.045)\end{array}$ & $\begin{array}{c}0.091 * * * \\
(0.049)\end{array}$ & $\begin{array}{c}0.012 \\
(0.041)\end{array}$ \\
\hline Position D & $\begin{array}{c}-0.287 * * * \\
(0.222)\end{array}$ & $\begin{array}{c}-0.126 * * * \\
(0.043)\end{array}$ & $\begin{array}{c}0.124 * * * \\
(0.063)\end{array}$ & $\begin{array}{c}-0.041^{*} \\
(0.041)\end{array}$ \\
\hline Position E & $\begin{array}{c}-0.525^{* * * *} \\
(0.165)\end{array}$ & $\begin{array}{c}-0.162 * * * \\
(0.043)\end{array}$ & $\begin{array}{c}0.156 * * * \\
(0.076)\end{array}$ & $\begin{array}{c}-0.073^{* * *} \\
(0.041)\end{array}$ \\
\hline Trustworthiness & $\begin{array}{c}0.108 * * * \\
(0.227)\end{array}$ & $\begin{array}{l}-0.015 \\
(0.096)\end{array}$ & $\begin{array}{c}-0.045^{* *} \\
(0.101)\end{array}$ & $\begin{array}{l}-0.025 \\
(0.089)\end{array}$ \\
\hline Medium Rainfall & & $\begin{array}{c}0.317 * * * \\
(0.025)\end{array}$ & $\begin{array}{c}0.316^{* * *} \\
(0.027)\end{array}$ & $\begin{array}{c}0.314 * * * \\
(0.022)\end{array}$ \\
\hline High Rainfall & $\begin{array}{c}0.587 * * * \\
(0.176)\end{array}$ & $\begin{array}{c}0.440 * * * \\
(0.037)\end{array}$ & $\begin{array}{c}0.482^{* * * *} \\
(0.038)\end{array}$ & $\begin{array}{c}0.458 * * * \\
(0.033)\end{array}$ \\
\hline UUB NG & & $\begin{array}{c}-0.463 * * \\
(0.015)\end{array}$ & & $\begin{array}{l}-0.289 \\
(0.641)\end{array}$ \\
\hline UUB ESR & & & $\begin{array}{c}0.886 * * * \\
(0.167)\end{array}$ & $\begin{array}{c}0.621 \\
(5.616)\end{array}$ \\
\hline Round & & 0.006 & -0.015 & $-0.035 * *$ \\
\hline
\end{tabular}

(con'd)

\begin{tabular}{|c|c|c|c|c|}
\hline Constant & $\begin{array}{c}0.707 * * * \\
(0.186)\end{array}$ & $\begin{array}{c}(0.004) \\
0.045 \\
(0.106)\end{array}$ & $\begin{array}{c}(0.006) \\
-0.443^{* *} \\
(0.147)\end{array}$ & $\begin{array}{c}(0.003) \\
0.102 \\
(0.097)\end{array}$ \\
\hline \multicolumn{5}{|l|}{ UUB } \\
\hline Netgain $\mathrm{t}-1$ & & $\begin{array}{c}-0.979 * * \\
(4.146)\end{array}$ & & $\begin{array}{l}-0.959 \\
(4.167)\end{array}$ \\
\hline Netgain $\mathrm{t}-2$ & & $\begin{array}{c}-0.035^{*} \\
(0.167)\end{array}$ & & $\begin{array}{l}-0.037 \\
(0.155)\end{array}$ \\
\hline ESR t-1 & & & $\begin{array}{c}0.194^{* * *} \\
(0.046)\end{array}$ & $\begin{array}{c}0.184 \\
(0.187)\end{array}$ \\
\hline ESR t-1 & & & $\begin{array}{c}0.334 * * * \\
(0.056)\end{array}$ & $\begin{array}{c}0.388 \\
(0.397)\end{array}$ \\
\hline \multicolumn{5}{|l|}{ Model Statistics } \\
\hline $\mathrm{N}$ & 80.000 & 1040.000 & 990.000 & 990.000 \\
\hline Chi2 & 8.6 & 270.074 & 797.978 & 241.653 \\
\hline Df(deg Freedom) & 9.000 & 26.000 & 26.000 & 26.000 \\
\hline P-value & 0.473 & 0.000 & 0.000 & 0.000 \\
\hline \multicolumn{5}{|c|}{$\begin{array}{l}\text { Note: } *=\text { significant at the } 95 \% \text { level, } * *=\text { significant at the } 99 \% \text { level, and } \\
* * *=\text { significant at the } 99.9 \% \text { level. Bootstrapped standard errors are in } \\
\text { parentheses. All models are controlled for effects between and within } \\
\text { groups. Position is compared with position A. Sequence and Variability are } \\
\text { compared with Sequence NLH x No Variability. Rainfall is compared with } \\
\text { low rainfall. LHN, low, high, and no variability; NHL, no, high, and low } \\
\text { variability; NLH, no, low, and high variability; NG, net gain; ESR, equal- } \\
\text { share ratio; UUB, upstream users' behavior. }\end{array}$} \\
\hline
\end{tabular}

which extraction inequality is seen as the main factor driving reduced investments in the common-pool resource (Janssen et al. 2012, Cardenas et al. 2013).

At the group level in round 1 (Table 5), the only significant variable affecting investments was the change in variability sequence. In rounds 2-15 the most important negative effect was extraction inequality. The greater the extraction inequality, the lower the group investment level. This result, once again, confirms previous findings on the importance of extraction inequality and its effect on collective action. Variability at the group level had an interesting double effect. On the one hand, when the variability sequence was the baseline NLH order, it had a positive effect on investment. However, in all other cases, variability reduced the investment level. The effect of high variability was significantly different from low and no variability when the sequence was LHNorNHL (Wald test $p<0.001$ ), confirming the results above for all models presented in Tables 4 and 5. However, when the sequence was no, low, and high variability (NLH), there was no difference between low and high variability, and the effect on investment was positive. Unfortunately, we have no theoretical explanation for why this was the case. We can only speculate that the positive effect from variability might have been generated by an optimism that newly introduced variability following the no-variability phase might lead to better extraction opportunities. Finally, at the group level, risk aversion had a prominent role in positively affecting the investment level. A higher will to take risks within a group led to higher average group investment. This result is also in line with previous research on the effect of risk aversion on investment in variable conditions. 


\section{Assessing results robustness: a different statistical approach}

The differences between round 1 and rounds $2-15$ point to the importance of recognizing the simultaneous effects that investment and extraction decisions can have on each other over time. To assess such effects, we modeled the simultaneous causality between investment and extraction via equation 5 and equation 6 . This statistical model is also depicted in Figure 7.

Fig. 7. Diagrammatic representation of the statistical model represented in equation 5. Arrows represent the direction of dependencies as modeled. Arrows on the error terms indicate correction for autocorrelation and correlation between them.

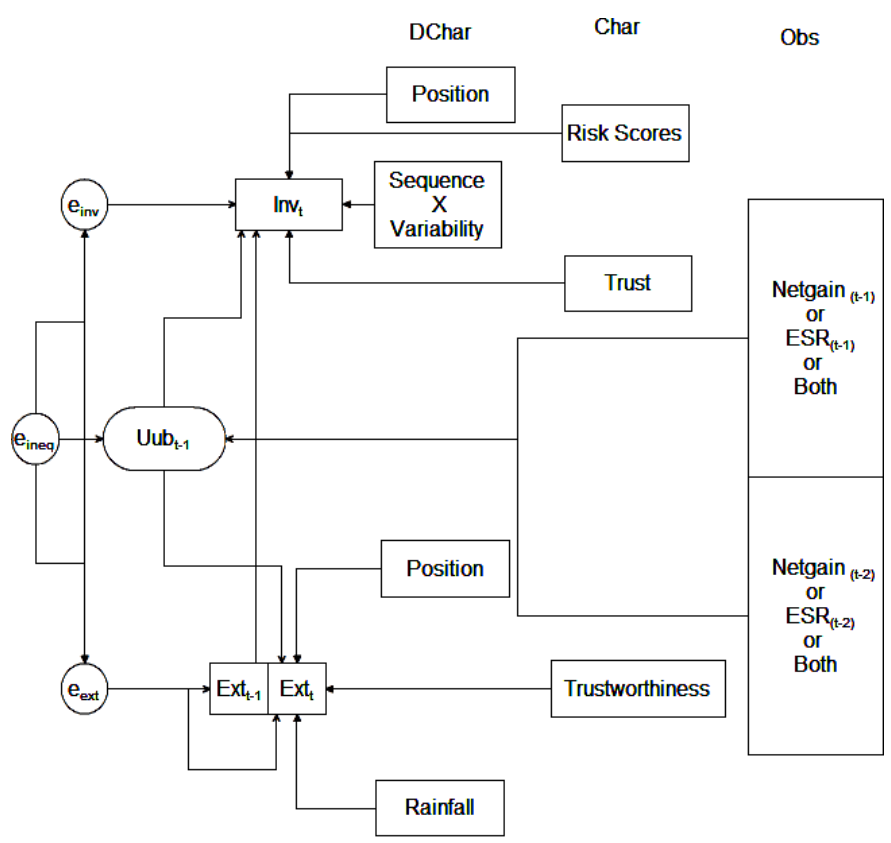

$$
\left\{\begin{array}{l}
\operatorname{Inv}_{i, t}=b_{0}+\overrightarrow{b x_{1} \text { DChar }_{i}}+\overrightarrow{\text { bx }_{2} \operatorname{Char}_{i}}+b x_{3} U u b_{i, t-1}+E x t_{i, t-1}+G_{i}+\varepsilon_{i, t} \\
\operatorname{Ext}_{i, t}=z_{0}+\overrightarrow{z x_{1} \text { DChar }_{i}}+\overrightarrow{z x_{2} \operatorname{Char}_{i}}+z x_{3} U u b_{i, t-1}+\operatorname{Inv} v_{i, t}+G_{i}+v_{i, t}
\end{array}\right.
$$

where

$$
U u b_{i, t}=c_{1} O b s_{i, t}+c_{2} O b s_{i, t-1}+G_{i}+v_{i, t}
$$

and investment (Inv) and extraction (Ext) depend on:

- a vector of dummy characteristics (DChar), representing position, sequence-variability interaction, and rainfall;

- a vector of personal characteristics (Char) such as trust, trustworthiness, and risk aversion; and

- the effect from observed upstream users' behavior (Uub; equation 6).

The effect of upstream users' behavior is dependent on the observed behavior $(O b s)$ given by simple indicators such as ESR (as per equation 1) and net gain (as per equation 2). $G_{i}$ is a variable that controls for between-group variations. Finally $\varepsilon_{i, t}, u_{i, t}$ and $v_{i, t}$ represent the error terms for each of the equations.
To assess the importance of the explanatory variables, we report the standardized coefficients stemming from the model described above (Table 6) and the standardized total effects to allow for comparison between variables (strength of effects; Table 7). Although the standard coefficients traditionally reported in statistical models take only direct effects into account, the total effects presented here include the direct and indirect effects of an explanatory variable on the dependent variable. In our model as shown in Figure 7, trust directly affected investments; however, trust could also affect extraction decisions indirectly via the previously made investment decision. Likewise, rainfall impacted extraction at $t$; however, it could also have an indirect effect on investment at $t+1$.

To assess model fit, we report the overall $R^{2}$ and goodness-of-fit test (or $\mathrm{X}^{2}$ test). The information and results given by the system represented in equation 5 serve as an important robustness check of the models used in equations 3 and 4. Details for the model estimation in equation 5 and Figure 7 are provided in Appendix 1 (Statistical Model). Tables 6 and 7 report the results for equation 5 under three different specifications. Changes in the model specification are targeted toward the measure of the observed behavior variables: net gain, equal-share ratio, and both net gain and ESR together. We report results for the first round (model 1) separately to assess whether trust, risk aversion, and variability have a different effect at the beginning of the experiment than in subsequent rounds.

Tables 6 and 7 confirm the results for investments; however, they also account for another layer of complexity that exists in these kinds of experiments: they explicitly assess the interdependencies between investment and extraction over time, given a set of independent variables. It is notable that in round one there was no positive relationship between investment and extraction. A plausible explanation lies in the nature of the resource in the experiment. In a situation where the group investment does not reach a specific threshold (as reported in Table 2), investment does not lead to the generation of a resource, and consequently, the extraction level will be zero. If this happens, the first round sets in motion a negative path toward purely selfish behavior (i.e., zero investments). Another plausible explanation is that, at least in round one, individuals are more prone to be generous because the behavior of other group members cannot be known.

The results of round one, however, were not duplicated in subsequent rounds. As a result, no matter what is used to proxy observed behavior, we can confidently affirm that trust loses its importance, transferring causal importance to the observed actions of the upstream users. This latter result is the logical consequence of repeated interactions between individuals. The amount invested is always highly significant and positively related to the amount extracted, and the amount extracted in a previous round is always highly significant and positively related to the amount invested in the subsequent round. This relationship is not surprising, and it highlights the importance of the behavioral interdependencies involved in sequential investment-extraction decisions.

We need to acknowledge that the more complex the experiment, the more complex the analysis will be. All statistical estimation is prone to bias and efficiency issues; however, the multiple tools used here allow us to be confident in our analysis and in the robustness of our results. 
Table 7. Results for the model reported in equation 5 at the individual level. Coefficients represent the total effect of variables of interest (direct and indirect effects).

\begin{tabular}{|c|c|c|c|c|c|c|c|c|}
\hline \multirow[t]{3}{*}{ Variable } & \multicolumn{2}{|c|}{$\mathrm{R} 1$} & \multicolumn{2}{|c|}{$\mathrm{NG}$} & \multicolumn{2}{|c|}{ ESR } & \multicolumn{2}{|c|}{ All } \\
\hline & \multicolumn{2}{|c|}{ Round 1} & \multicolumn{6}{|c|}{ Rounds 2-15 } \\
\hline & inv & ext & inv & Ext & inv & ext & inv & Ext \\
\hline Extraction $(\mathrm{t}-1)^{+\mathrm{e}}$ & & & $\begin{array}{c}2.584 * * * \\
(0.046)\end{array}$ & $\begin{array}{c}0.666^{* * *} * \\
(0.055)\end{array}$ & $\begin{array}{c}0.371 * * * \\
(0.020)\end{array}$ & $\begin{array}{c}0.282 * * * \\
(0.028)\end{array}$ & $\begin{array}{c}2.667 * * * \\
(0.055)\end{array}$ & $\begin{array}{c}0.310^{* * *} * \\
(0.055)\end{array}$ \\
\hline Investment & & $\begin{array}{c}-0.556^{* * *} \\
(0.174)\end{array}$ & & $\begin{array}{c}0.258 * * * \\
(0.021)\end{array}$ & & $\begin{array}{c}0.760 * * * \\
(0.085)\end{array}$ & & $\begin{array}{c}0.116^{* * * *} \\
(0.021)\end{array}$ \\
\hline Position B & $\begin{array}{c}0.053 \\
(0.136)\end{array}$ & $\begin{array}{l}-0.078 \\
(0.138)\end{array}$ & $\begin{array}{c}-0.012 \\
(0.034)\end{array}$ & $\begin{array}{c}-0.079 * * * \\
(0.040)\end{array}$ & $\begin{array}{c}-0.054^{* * *} * \\
(0.033)\end{array}$ & $\begin{array}{l}-0.006 \\
(0.041)\end{array}$ & $\begin{array}{l}-0.014 \\
(0.031)\end{array}$ & $\begin{array}{l}-0.017 \\
(0.036)\end{array}$ \\
\hline Position C & $\begin{array}{l}-0.047 \\
(0.136)\end{array}$ & $\begin{array}{l}-0.009 \\
(0.110)\end{array}$ & $\begin{array}{l}-0.005 \\
(0.036)\end{array}$ & $\begin{array}{c}-0.048^{*} \\
(0.046)\end{array}$ & $\begin{array}{c}-0.064 * * * \\
(0.037)\end{array}$ & $\begin{array}{l}0.042^{*} \\
(0.047)\end{array}$ & $\begin{array}{l}-0.007 \\
(0.033)\end{array}$ & $\begin{array}{c}0.011 \\
(0.042)\end{array}$ \\
\hline Position D & $\begin{array}{l}-0.017 \\
(0.184)\end{array}$ & $\begin{array}{c}-0.277 * * * \\
(0.141)\end{array}$ & $\begin{array}{c}-0.055^{* * *} \\
(0.039)\end{array}$ & $\begin{array}{c}-0.140 * * * \\
(0.043)\end{array}$ & $\begin{array}{c}-0.186^{* * *} \\
(0.038)\end{array}$ & $\begin{array}{l}-0.018 \\
(0.045)\end{array}$ & $\begin{array}{c}-0.060 * * * \\
(0.036)\end{array}$ & $\begin{array}{c}-0.048 * * \\
(0.042)\end{array}$ \\
\hline Position E & $\begin{array}{c}-0.268^{* * *} \\
(0.145)\end{array}$ & $\begin{array}{c}-0.376^{* * *} \\
(0.133)\end{array}$ & $\begin{array}{c}-0.086^{* * *} * \\
(0.044)\end{array}$ & $\begin{array}{c}-0.184 * * * \\
(0.042)\end{array}$ & $\begin{array}{c}-0.271^{* * *} * \\
(0.045)\end{array}$ & $\begin{array}{c}-0.050^{* *} \\
(0.046)\end{array}$ & $\begin{array}{c}-0.088^{* * *} \\
(0.044)\end{array}$ & $\begin{array}{c}-0.083^{* * *} \\
(0.041)\end{array}$ \\
\hline NLH x LowVar ${ }^{+e}$ & & & $\begin{array}{l}-0.013 \\
(0.064)\end{array}$ & $\begin{array}{l}-0.003 \\
(0.016)\end{array}$ & $\begin{array}{c}0.018 \\
(0.052)\end{array}$ & $\begin{array}{c}0.014 \\
(0.042)\end{array}$ & $\begin{array}{c}0.004 \\
(0.061)\end{array}$ & $\begin{array}{c}0.001 \\
(0.007)\end{array}$ \\
\hline $\mathrm{NLH} \times \mathrm{HighVar}^{+\mathrm{e}}$ & & & $\begin{array}{c}0.042 \\
(0.074)\end{array}$ & $\begin{array}{c}0.011 \\
(0.019)\end{array}$ & $\begin{array}{l}0.048^{*} \\
(0.063)\end{array}$ & $\begin{array}{l}0.036^{*} \\
(0.049)\end{array}$ & $\begin{array}{c}0.042 \\
(0.071)\end{array}$ & $\begin{array}{c}0.005 \\
(0.009)\end{array}$ \\
\hline LHNorNHL x NoVar ${ }^{+e}$ & $\begin{array}{c}-0.338^{* * *} \\
(0.096)\end{array}$ & $\begin{array}{c}0.188^{* * * *} \\
(0.125)\end{array}$ & $\begin{array}{c}-0.067 * * \\
(0.066)\end{array}$ & $\begin{array}{l}-0.017 \\
(0.017)\end{array}$ & $\begin{array}{c}-0.184 * * * \\
(0.057)\end{array}$ & $\begin{array}{c}-0.140 * * * \\
(0.064)\end{array}$ & $\begin{array}{c}-0.054^{*} \\
(0.065)\end{array}$ & $\begin{array}{l}-0.006 \\
(0.009)\end{array}$ \\
\hline LHNorNHL x LowVar ${ }^{+e}$ & $\begin{array}{c}-0.058 \\
(0.111)\end{array}$ & $\begin{array}{c}0.032 \\
(0.094)\end{array}$ & $\begin{array}{c}-0.077^{* *} \\
(0.065)\end{array}$ & $\begin{array}{c}-0.020^{* *} \\
(0.016)\end{array}$ & $\begin{array}{c}-0.113^{* * *} \\
(0.057)\end{array}$ & $\begin{array}{c}-0.086^{* * *} \\
(0.056)\end{array}$ & $\begin{array}{l}-0.048^{*} \\
(0.062)\end{array}$ & $\begin{array}{l}-0.006 \\
(0.008)\end{array}$ \\
\hline LHNorNHL $x$ HighVar ${ }^{+e}$ & & & $\begin{array}{c}-0.087 * * * \\
(0.057)\end{array}$ & $\begin{array}{c}-0.022^{* *} \\
(0.015)\end{array}$ & $\begin{array}{c}-0.215^{* * *} \\
(0.052)\end{array}$ & $\begin{array}{c}-0.163^{* * *} \\
(0.055)\end{array}$ & $\begin{array}{c}-0.077^{* *} \\
(0.055)\end{array}$ & $\begin{array}{c}-0.009^{* *} \\
(0.008)\end{array}$ \\
\hline Medium Rainfall & & & & $\begin{array}{c}0.317^{* * * *} \\
(0.025)\end{array}$ & & $\begin{array}{c}0.316^{* * * *} \\
(0.027)\end{array}$ & & $\begin{array}{c}0.314 * * * \\
(0.022)\end{array}$ \\
\hline High Rainfall & & $\begin{array}{c}0.587 * * * \\
(0.176)\end{array}$ & & $\begin{array}{c}0.440^{* * *} \\
(0.037)\end{array}$ & & $\begin{array}{c}0.482^{* * *} \\
(0.038)\end{array}$ & & $\begin{array}{c}0.458 * * * \\
(0.033)\end{array}$ \\
\hline Normalized Risk Scores $^{+\mathrm{e}}$ & $\begin{array}{c}0.102^{* *} \\
(0.206)\end{array}$ & $\begin{array}{c}-0.057^{* *} \\
(0.149)\end{array}$ & $\begin{array}{c}0.007 \\
(0.105)\end{array}$ & $\begin{array}{c}0.002 \\
(0.026)\end{array}$ & $\begin{array}{c}0.025 \\
(0.093)\end{array}$ & $\begin{array}{c}0.019 \\
(0.076)\end{array}$ & $\begin{array}{l}-0.007 \\
(0.097)\end{array}$ & $\begin{array}{l}-0.001 \\
(0.012)\end{array}$ \\
\hline Trust $+\mathrm{e}$ & $\begin{array}{c}0.378 * * * \\
(0.077)\end{array}$ & $\begin{array}{c}-0.210^{* * *} \\
(0.129)\end{array}$ & $\begin{array}{l}-0.010 \\
(0.041)\end{array}$ & $\begin{array}{l}-0.003 \\
(0.010)\end{array}$ & $\begin{array}{c}0.036^{* *} \\
(0.040)\end{array}$ & $\begin{array}{c}0.027 * * \\
(0.030)\end{array}$ & $\begin{array}{l}-0.006 \\
(0.039)\end{array}$ & $\begin{array}{l}-0.001 \\
(0.005)\end{array}$ \\
\hline Trustworthiness & & $\begin{array}{c}0.108^{* *} \\
(0.227)\end{array}$ & & $\begin{array}{l}-0.015 \\
(0.096)\end{array}$ & & $\begin{array}{c}-0.045^{* *} \\
(0.101)\end{array}$ & & $\begin{array}{l}-0.025 \\
(0.089)\end{array}$ \\
\hline Round & & & $\begin{array}{c}-0.066 * * \\
(0.006)\end{array}$ & $\begin{array}{l}-0.011 \\
(0.004)\end{array}$ & $\begin{array}{c}-0.100 * * * \\
(0.006)\end{array}$ & $\begin{array}{c}-0.091^{* * *} \\
(0.004)\end{array}$ & $\begin{array}{c}-0.064 * * \\
(0.005)\end{array}$ & $\begin{array}{c}-0.042 * * \\
(0.004)\end{array}$ \\
\hline UUB NG & & & $\begin{array}{c}2.333^{* *} \\
(0.078)\end{array}$ & $\begin{array}{l}0.138^{*} \\
(0.005)\end{array}$ & & & $\begin{array}{c}2.501 \\
(5.330)\end{array}$ & $\begin{array}{c}0.002 \\
(0.018)\end{array}$ \\
\hline UUB ESR & & & & & $\begin{array}{c}-0.166^{* * *} \\
(0.051)\end{array}$ & $\begin{array}{c}0.760 * * * \\
(0.144)\end{array}$ & $\begin{array}{c}0.036 \\
(0.326)\end{array}$ & $\begin{array}{c}0.625 \\
(5.654)\end{array}$ \\
\hline $\operatorname{Netgain}(\mathrm{t}-1)^{++}$ & & & $\begin{array}{c}-2.283^{* * *} \\
(0.047)\end{array}$ & $\begin{array}{c}-0.135^{* *} \\
(0.051)\end{array}$ & & & $\begin{array}{c}-2.399 * * * \\
(0.055)\end{array}$ & $\begin{array}{l}-0.002 \\
(0.046)\end{array}$ \\
\hline $\operatorname{Netgain}(\mathrm{t}-2)^{++}$ & & & $\begin{array}{c}-0.081^{* * *} \\
(0.018)\end{array}$ & $\begin{array}{l}-0.005^{*} \\
(0.002)\end{array}$ & & & $\begin{array}{c}-0.091^{* * *} \\
(0.017)\end{array}$ & $\begin{array}{c}0.000 \\
(0.002)\end{array}$ \\
\hline $\operatorname{ESR}(\mathrm{t}-1)^{++}$ & & & & & $\begin{array}{c}-0.032 * * * \\
(0.009)\end{array}$ & $\begin{array}{c}0.148 * * * \\
(0.027)\end{array}$ & $\begin{array}{c}0.007 \\
(0.006)\end{array}$ & $\begin{array}{c}0.115^{* * * *} \\
(0.026)\end{array}$ \\
\hline $\operatorname{ESR}(\mathrm{t}-2)^{++}$ & & & & & $\begin{array}{c}-0.055^{* * *} \\
(0.012)\end{array}$ & $\begin{array}{c}0.254^{* * *} \\
(0.025)\end{array}$ & $\begin{array}{c}0.014 \\
(0.012)\end{array}$ & $\begin{array}{c}0.242 * * * \\
(0.023)\end{array}$ \\
\hline $\mathrm{N}$ & 80 & & 1040 & & 990 & & 990 & \\
\hline chi2 & 0.473 & & 0.000 & & 0.000 & & 0.000 & \\
\hline R2overall & 0.507 & & 0.999 & & 0.786 & & 0.999 & \\
\hline Discrepancy & 0.108 & & 0.260 & & 0.806 & & 0.244 & \\
\hline
\end{tabular}




\section{CONCLUSION}

Many small-scale irrigation systems around the world face the dual problems of how to collectively construct the needed infrastructure for the common-pool resource and how to effectively and equitably share that resource. Upstream farmers possess privileged access to the water in the system, but they are also dependent on the contributions of the downstream farmers to build and maintain the infrastructure that carries the needed water. Thus, an important challenge in managing common-pool resources is how to ensure collective action so as to maintain the resource at a sustainable level, while preventing individuals in privileged positions from taking advantage of the general effort. Collective action is especially challenging in systems that are naturally prone to asymmetries because of heterogeneity caused by biophysical contexts (Anderies et al. 2011). The complexity of the coupled interactions between the ecological natural processes (such as the risks posed by environmental conditions) and the decisions of the resource users complicate matters further (Anderies et al. 2004).

We made a first attempt to disentangle the interplay between variability, trust, upstream user behavior, and resource viability via a simple asymmetric common-pool resource game. The experiment performed could be analyzed in many different ways. The richness of the data is a benefit, but this richness can also be daunting when it comes to understanding the dynamics of the system. Given the complexity rising from the interplay of path dependency, personal characteristics, and variability, we need to caution against generalizing experiments performed in a laboratory setting. Still, we believe that our experiment allows us to draw some preliminary conclusions about the relationship between environmental variability and the feedback loop between upstream user behavior and reciprocity-type responses.

Effects from reactions to upstream users' behavior take precedence over initial personal characteristics and variability in the resource. This effect, especially for investments, is clear and secondary only to the positional asymmetry effect. This result confirms, even in absence of communication, the outcomes presented by Anderies et al. (2013). The complexity of the investment extraction cycle is, however, not so easy to disentangle. Investment and extraction decisions continuously influence each other, whether an individual is more concerned about gains (net gains) or equity (ESR), or if there is extraction inequality (extraction gini coefficient). The strength of path dependency and the importance of upstream users' behavior in the irrigation context are also confirmed by the difference exhibited between the first and subsequent rounds of the game. As expected, trust at the individual level is a prominent factor, affecting decisions on investment levels to maintain and generate the resource; however, it quickly gives way to the importance of observed behavior. The importance of behavioral characteristics and interplay between observed environmental and personal characteristics is also confirmed by the results presented in Baggio and Janssen (2013). What other individuals do greatly affects one's own decisions. Where individuals are located in the system is a highly significant factor in their willingness to contribute, and the tail enders are highly dependent on the head enders to maintain share equality.

From the experiments performed, we can affirm that (1) upstream users' behavior is by far the most important variable in determining the outcome of collective action; (2) environmental variability (i.e. risk level in investing in the resource) has little effect on individual investment and extraction levels; and (3) the action-reaction feedback is fundamental in determining the success or failure of communities, at least within the limits of our study. Our results confirm the basic dynamics of Ostrom's behavioral model of collective action (Ostrom 1998).

Responses to this article can be read online at: http://www.ecologyandsociety.org/issues/responses. $\mathrm{php} / 7772$

\section{Acknowledgments:}

We acknowledge financial support by the National Science Foundation, grant numbers SES-0748632 and GEO-1115054. We also would like to thank Jennifer Fraser and four anonymous referees for their comments and insights.

\section{LITERATURE CITED}

Allison, S. T., and D. M. Messick. 1990. Social decision heuristics in the use of shared resources. Journal of Behavioral Decision Making 3(3):195-204 http://dx.doi.org/10.1002/bdm.3960030304

Anderies, J. M., and M. A. Janssen. 2011. The fragility of robust social-ecological systems. Global Environmental Change 21 (4):1153-1156 http://dx.doi.org/10.1016/j.gloenvcha.2011.07.004

Anderies, J. M., M. A. Janssen, F. Bousquet, J.-C. Cardenas, D. Castillo, M.-C. Lopez, R. Tobias, B. Vollan, and A. Wutich. 2011. The challenge of understanding decisions in experimental studies of common pool resource governance. Ecological Economics 70 (9):1571-1579 http://dx.doi.org/10.1016/j.ecolecon.2011.01.011

Anderies, J. M., M. A. Janssen, A. Lee, and H. Wasserman. 2013. Environmental variability and collective action: experimental insights from an irrigation game. Ecological Economics 93:166-176. http://dx.doi.org/10.1016/j.ecolecon.2013.04.010

Anderies, J. M., M. A. Janssen, and E. Ostrom. 2004. A framework to analyze the robustness of social-ecological systems from an institutional perspective. Ecology and Society 9(1):18. [online] URL: http://www.ecologyandsociety.org/vol9/iss1/art18/

$\mathrm{Au}$, W. 2004. Criticality and environmental uncertainty in steplevel public goods dilemmas. Group Dynamics: Theory, Research, and Practice 8:40-61. http://dx.doi.org/10.1037/1089-2699.8.1.40

Baggio, J. A., and M.A. Janssen. 2013. Comparing agent-based models on experimental data of irrigation games. Pages 1742-1753 in R. Pasupathy, S.-H. Kim, A. Tolk, R. Hill, and M. E. Kuhl, editors. Simulation Conference (WSC), 2013 winter. IEEE Press, New York, New York, USA. http://dx.doi. org/10.1109/wsc.2013.6721555

Beckenkamp, M., H. Hennig-Schmidt, and F. P. Maier-Rigaud. 2007. Cooperation in symmetric and asymmetric prisoner's dilemma games (3/2007). MPI Collective Goods Preprint No. 2006/25. Max Planck Institute for Research on Collective Goods, Bonn, Germany. http://dx.doi.org/10.2139/ssrn.968942 
Berg, J., J. Dickhaut, and K. McCabe. 1995. Trust, reciprocity, and social history. Games and Economic Behavior 10:122-142. http://dx.doi.org/10.1006/game.1995.1027

Biel, A., and T. Gärling. 1995. The role of uncertainty in resource dilemmas. Journal of Environmental Psychology 15(3):221-233. http://dx.doi.org/10.1016/0272-4944(95)90005-5

Budescu, D. V., A. Rapoport, and R. Suleiman. 1990. Resource dilemmas with environmental uncertainty and asymmetric players. European Journal of Social Psychology 20(6):475-487. http://dx.doi.org/10.1002/ejsp.2420200603

Cardenas, J.-C., M. A. Janssen, and F. Bousquet. 2013. Dynamics of rules and resources: three new field experiments on water, forests and fisheries. Pages 319-345 in J. A. List and M. K. Price, editors. Handbook on experimental economics and the environment. Edward Elgar, Cheltenham, UK. http://dx.doi. org/10.4337/9781781009079.00020

Cifdaloz, O., A. Regmi, J. M. Anderies, and A. A. Rodriguez. 2010. Robustness, vulnerability, and adaptive capacity in smallscale social-ecological systems: the Pumpa Irrigation System in Nepal. Ecology and Society 15(3):39. [online] URL: http://www. ecologyandsociety.org/vol15/iss3/art39/

Gustafson, M., A. Biel, and T. Gärling. 2000. Egoism bias in social dilemmas with resource uncertainty. Group Processes \& Intergroup Relations 3:351-365. http://dx.doi.org/10.1177/13684$\underline{30200003004002}$

Holt, C. A., and S. K. Laury. 2002. Risk aversion and incentive effects. American Economic Review 92(5):1644-1655. http://dx. doi.org/10.1257/000282802762024700

Janssen, M. A., J. M. Anderies, and S. R. Joshi. 2011. Coordination and cooperation in asymmetric commons dilemmas. Experimental Economics 14(4):547-566. http://dx.doi. org/10.1007/s10683-011-9281-9

Janssen, M. A., F. Bousquet, J.-C. Cardenas, D. Castillo, and K. Worapimphong. 2012. Field experiments on irrigation dilemmas. Agricultural Systems 109:65-75. http://dx.doi.org/10.1016/j. agsy.2012.03.004

Messick, D. M., S. T. Allison, and C. D. Samuelson. 1988. Framing and communication effects on group members' responses to environmental and social uncertainty. Pages 677-700 in S. Maital, editor. Applied behavioral economics. Volume II. Wheatsheaf, Brighton, UK.

Ostrom, E. 1998. A behavioral approach to the rational choice theory of collective action: presidential address, American Political Science Association, 1997. American Political Science Review 92(1):1-22. http://dx.doi.org/10.2307/2585925

Ostrom, E., and R. Gardner. 1993. Coping with asymmetries in the commons: self-governing irrigation systems can work. Journal of Economic Perspectives 7(4):93-112. http://dx.doi.org/10.1257/ jep.7.4.93

Rapoport, A., D. V. Budescu, R. Suleiman, and E. Weg. 1992. Social dilemmas with uniformly distributed resources. Pages 43-57 in W. B. G. Liebrand, D. Messick, and H. Wilke, editors. Social dilemmas. Theoretical issues and research findings. Pergamon, Oxford, UK.
Walker, J. M., and R. Gardner. 1992. Probabilistic destruction of common-pool resources: experimental evidence. Economic Journal 102(414):1149-1161. http://dx.doi.org/10.2307/2234382

Wit, A., and H. Wilke. 1998. Public good provision under environmental and social uncertainty. European Journal of Social Psychology 28:249-256. http://dx.doi.org/10.1002/(SICI)1099-0992 (199803/04)28:2<249::AID-EJSP868>3.0.CO;2-J 


\section{Supplementary Material}

\section{Content Index:}

1. Supplementary Figures

2. Correlograms

3. Statistical Model

4. Experiment Instructions and Forms 


\section{Supplementary Figures:}

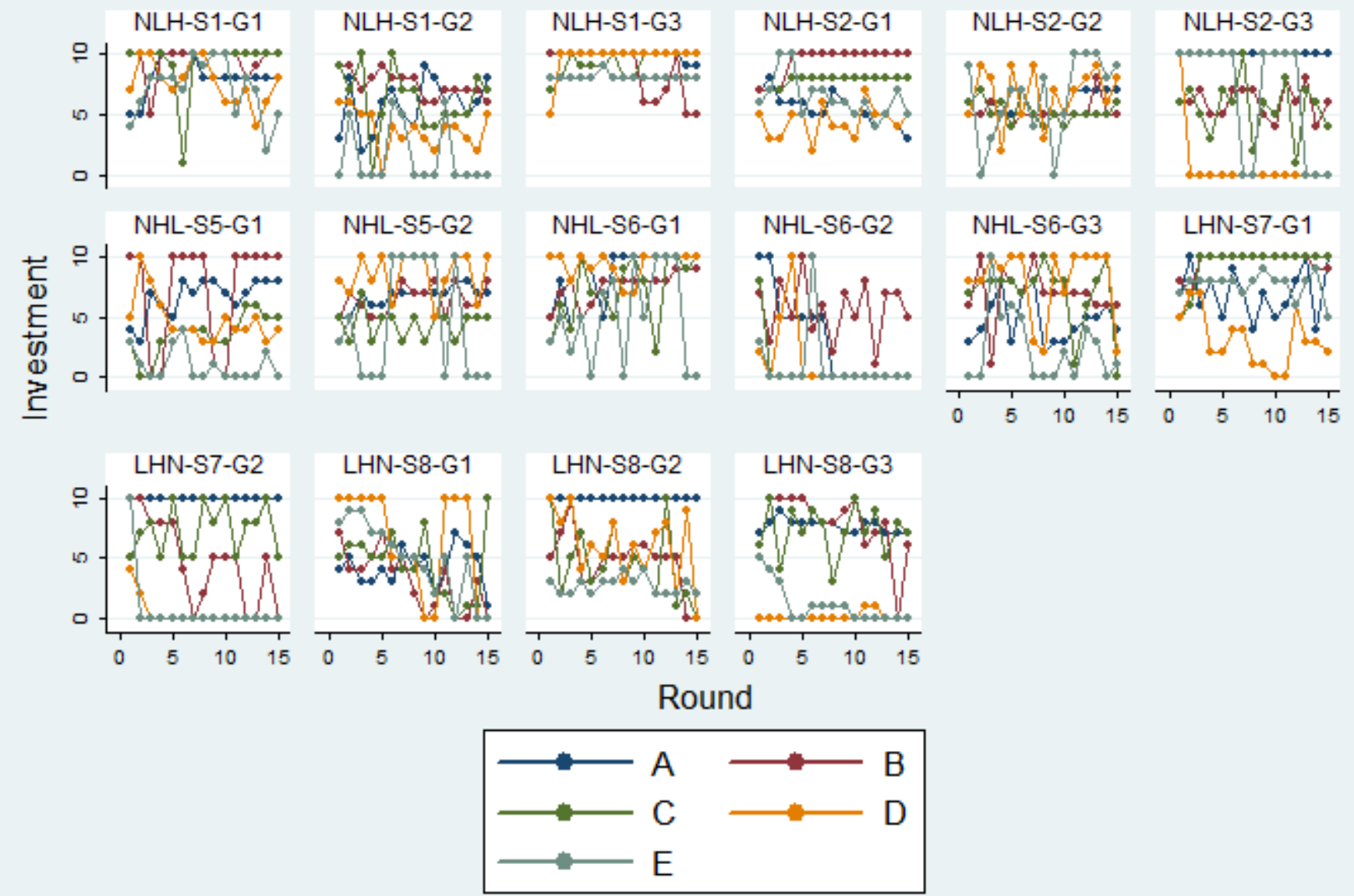

Graphs by Group ID

Figure S1: Investment per group per position. Each group is preceded by the treatment label (NLH = no, low and high Variability, $\mathrm{NHL}=$ no, high and low Variability; LHN = low, high and no Variability) 


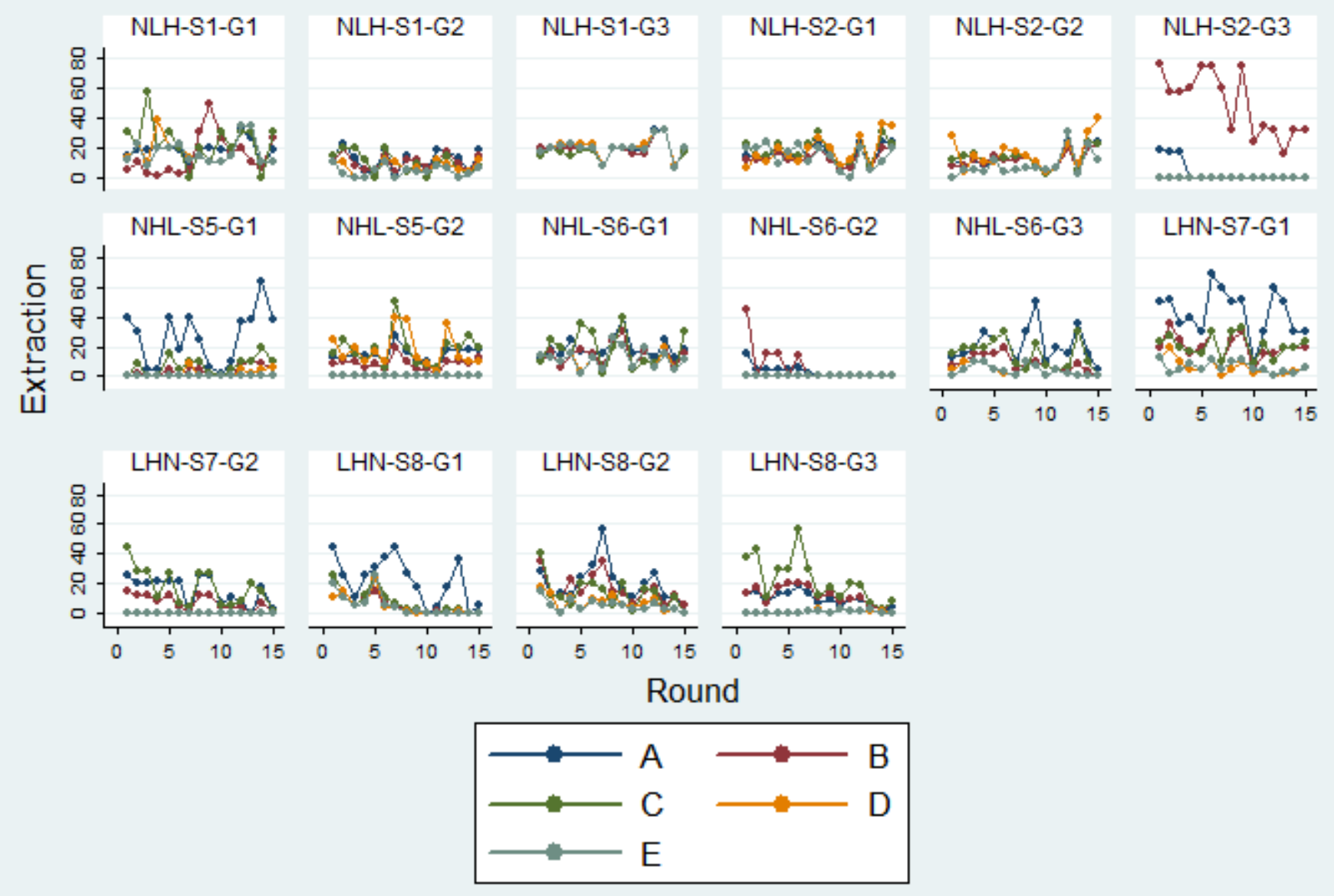

Graphs by Group ID

Figure S2: Extraction per group per position. Each group is preceded by the treatment label (NLH = no, low and high Variability, $\mathrm{NHL}=$ no, high and low Variability; LHN = low, high and no Variability) 


\section{Correlogram between variables}

Table S1: Correlogram for variables at the individual level (only continuous variables)

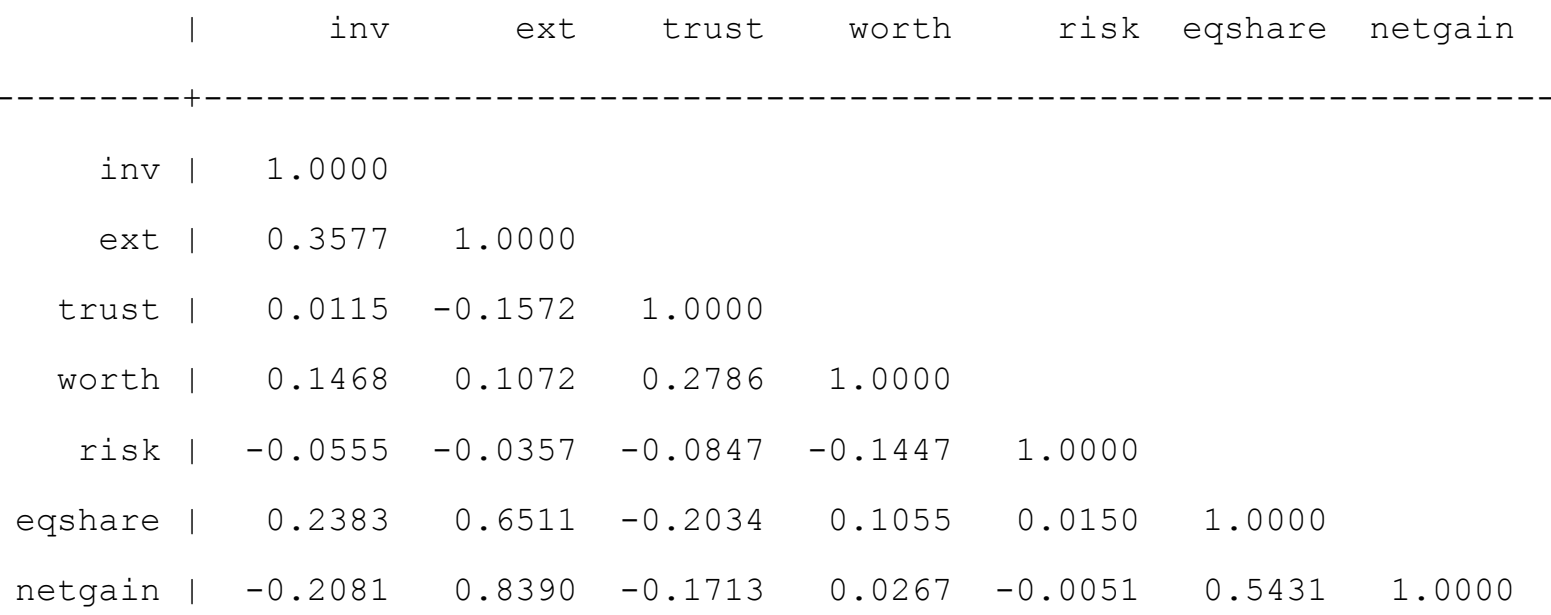

Table S2: Correlogram for variables at the group level (only continuous variables)

I avginv avgext avgtrust avgworth avgrisk extgini invgini

$\begin{array}{rrrrrrrr}\text { avginv | } & 1.0000 & & & & & & \\ \text { avgext I } & 0.7289 & 1.0000 & & & & & \\ \text { avgtrust I } & 0.0916 & 0.0048 & 1.0000 & & & & \\ \text { avgworth I } & 0.0755 & 0.0419 & 0.1795 & 1.0000 & & \\ \text { avgrisk I } & 0.3800 & 0.3073 & 0.0265 & 0.4214 & 1.0000 & \\ \text { extgini I } & -0.3270 & -0.3395 & 0.1409 & -0.0425 & 0.0193 & 1.0000 & \\ \text { invgini I } & -0.8733 & -0.6693 & 0.0300 & -0.0512 & -0.3220 & 0.3901 & 1.0000\end{array}$




\section{Statistical Model}

\section{Estimating a model that assesses feedbacks between investments and extractions}

The primary dependent variable in our statistical model, Investment, represents cooperation and level of collective action. Investment levels over time have been estimated explicitly addressing inter-temporal error term correlation and correlation of error terms present in the system depicted in eq 5 (i.e. correlation between $\varepsilon_{i, t}$ and $v_{i, t}$ ). Correcting for correlation between error terms follows empirical methodology used in economics (see for example Montalvo and Reynal-Querol 2005, Baggio and Papyrakis 2010). Correcting for correlation between error terms (in the manner proposed by Zellner (1962)), increases the efficiency of the estimated coefficients and decreases our system's sensitivity to specification errors.

Among other factors, Investment and Extraction decisions are a result of observed behavior measures such as Net Gain and Equal Share Ratio. The persistence of investment and extraction levels and consequentially, the metrics used for upstream user behavior (see Figures S1 and S2) bias our estimates. This bias is caused by the correlation between independent variables within the system and the actual system error terms (i.e. endogeneity). To avoid that bias we instrumented observed behavior (Net Gain, ESR) by using them as explanatory variables on upstream users' behavior $(U u b)$. In other words, the observation variable is considered a latent variable that is a linear function of a combination of investment and extractions (i.e., Net Gain, ESR, Gini coefficient of investment or extraction). Instrumenting the observed behavior variable and using its lags avoids these error-variable correlation problems. In other words, we are making sure that $U u b$ is not correlated with the systems' error terms. Therefore, we built a system of equations in which we took into account any correlation between error terms and corrected for autocorrelation.

To increase the robustness of our estimates we estimated the model in eq. 5 using the Asymptotically Distribution Free method (ADF) (Browne, 1984), a General Methods of Moments estimator (GMM). ADF (and GMM) allow estimates to be consistent and efficient when no distributional assumptions are made (i.e., when data are not jointly normal) (Hansen 1982). Using ADF increases robustness against correlation between the equation error terms and the explanatory variables used in the model--a condition that leads to endogeneity. However, ADF estimation requires, in general, large samples, because with small samples and complex models, ADF may lead to misleading results and achieving model convergence is problematic at best. In order to increase the reliability of our estimates and diminish convergence issues, we bootstraped our estimates and report bootstrapped standard errors over 500 repetitions.

\section{Collinearity - possible problem}

We checked variables for collinearity, finding a possible problem between average investment and investment Gini coefficient as hinted by the correlogram on averages. However, the two variables do not appear directly in the same equation, as investment Gini coefficient is used as an instrument and lagged.

\section{Total Effects}

The total effect is calculated summing the direct and indirect effect of an explanatory variable on the dependent variable. For example, if we follow Figure 7, trust affects investments directly, however, trust also affects extractions at time $t$, albeit indirectly through investment. Table 5, S3, S4 and S5 all report standardized total effects for the variables of interest. The use of standardized coefficients allows us to compare the effect of the different variables on investment and extractions even if variables are measured on different scales.

Table S2 reports total effect for the system estimated at the group level. Table S4 and S5 are a summary of effects for the model estimated at round 1 and the model estimated with the different specifications: with Net Gain, with Equal Share Ratio, and with both for the individual level; and investment Gini coefficient, Extraction 
Gini coefficient and both for the group level. Tables S4 and S5 report standardized total effect for the first Round and the average, minimum and maximum standardized total effects for the NG, ESR and All (and Inv, Ext models for the group level) models as in Table 5 and S3. Table S4 and S5 also report how many times (in proportion) a variable was deemed significant in the ESR, NG and All models (or Inv, Ext and All for the group models), and if their effect is consistent (i.e., the fraction of times a variable was positive or negative, depending on the slight changes in the model specification). $\mathrm{N}$ represents the number of times a specific explanatory variable was included in the three different model specification (individual and group level).

\section{References for Statistical Model Estimation and Justification:}

Baggio, J. A., and E. Papyrakis. 2010. Ethnic diversity, property rights, and natural resources. The Developing Economies, 48(4): 473-495.

Browne, M. W. 1984. Asymptotically distribution-free methods for the analysis of covariance structures. British Journal of Mathematical and Statistical Psychology, 37(1): 62-83

Hansen, L. P. 1982. Large sample properties of generalized method of moments estimators. Econometrica, 50(4): 1029-1054.

Montalvo, J. G., and M. Reynal-Querol. 2005. Ethnic Diversity and Economic Development. Journal of Development Economics 76(2): 293-323.

Zellner, A. 1962. An Efficient Method of Estimating Seemingly Unrelated Regressions and Test for Aggregation Bias. Journal of the American Statistical Association 57(298): 348-68. 
Table S3. Results for the Model reported in eq. 3 at the group level.

\begin{tabular}{|c|c|c|c|c|c|c|c|c|}
\hline \multirow{2}{*}{ Variable } & \multicolumn{2}{|c|}{$\mathrm{R} 1$} & \multicolumn{2}{|c|}{ Inv } & \multicolumn{2}{|c|}{ Ext } & \multicolumn{2}{|c|}{ All } \\
\hline & avginv & avgext & avginv & avgext & avginv & avgext & avginv & avgext \\
\hline \multirow[t]{2}{*}{ Avg Extraction ${ }_{\mathrm{t}-1}+\mathrm{e}$} & & & $0.241^{*}$ & $0.198 *$ & $0.431^{*}$ & $0.289 *$ & $0.195^{*}$ & $0.156^{*}$ \\
\hline & & & $(0.018)$ & (0.017) & $(0.016)$ & $(0.013)$ & $(0.017)$ & $(0.015)$ \\
\hline \multirow[t]{2}{*}{ Avg Investment } & & 0.563 & & $0.819 *$ & & $0.671^{*}$ & & $0.800 *$ \\
\hline & & $(0.501)$ & & (0.036) & & $(0.013)$ & & $(0.033)$ \\
\hline \multirow[t]{2}{*}{ Low Variability+e } & $0.570^{*}$ & 0.321 & $0.092^{*}$ & $0.076^{*}$ & 0.034 & 0.023 & $0.043^{*}$ & $0.035^{*}$ \\
\hline & $(0.106)$ & $(0.378)$ & $(0.043)$ & (0.041) & $(0.040)$ & (0.029) & $(0.038)$ & $(0.033)$ \\
\hline \multirow[t]{2}{*}{ High Variability ${ }^{+e}$} & & & $0.065^{*}$ & $0.053^{*}$ & $0.099 *$ & $0.067^{*}$ & $0.089 *$ & $0.071 *$ \\
\hline & & & $(0.046)$ & $(0.042)$ & (0.039) & $(0.028)$ & $(0.043)$ & $(0.039)$ \\
\hline \multirow[t]{2}{*}{ Normal Rainfall } & & & & $0.434^{*}$ & & $0.446 *$ & & $0.439 *$ \\
\hline & & & & (0.011) & & (0.009) & & (0.011) \\
\hline \multirow[t]{2}{*}{ High Rainfall } & & 0.478 & & $0.748^{*}$ & & $0.754^{*}$ & & $0.750 *$ \\
\hline & & (0.659) & & $(0.022)$ & & $(0.022)$ & & $(0.021)$ \\
\hline \multirow[t]{2}{*}{ Treatment $^{+e}$} & $-0.706 *$ & -0.398 & $-0.093^{*}$ & $-0.076^{*}$ & $-0.215^{*}$ & $-0.144 *$ & $-0.108^{*}$ & $-0.086^{*}$ \\
\hline & $(0.075)$ & $(0.411)$ & $(0.028)$ & $(0.024)$ & $(0.025)$ & $(0.017)$ & $(0.029)$ & $(0.024)$ \\
\hline \multirow[t]{2}{*}{ Avg Normalized Risk Scores ${ }^{+e}$} & $-0.032 *$ & -0.018 & $0.145^{*}$ & $0.118^{*}$ & $0.307^{*}$ & $0.206^{*}$ & $0.219 *$ & $0.175^{*}$ \\
\hline & $(0.001)$ & (0.509) & $(0.687)$ & $(0.640)$ & $(0.689)$ & $(0.522)$ & $(0.694)$ & $(0.744)$ \\
\hline \multirow[t]{2}{*}{ Avg Trust $+\mathrm{e}$} & $-0.223 *$ & -0.125 & $0.074^{*}$ & $0.061^{*}$ & $0.066^{*}$ & $0.044 *$ & $0.087^{*}$ & $0.069 *$ \\
\hline & $(0.007)$ & $(1.266)$ & $(0.225)$ & (0.193) & $(0.180)$ & $(0.132)$ & $(0.200)$ & (0.176) \\
\hline \multirow[t]{2}{*}{ Avg Trustworthiness } & & -0.062 & & 0.007 & & $0.022 *$ & & 0.001 \\
\hline & & $(1.916)$ & & $(0.115)$ & & $(0.103)$ & & $(0.116)$ \\
\hline \multirow[t]{2}{*}{ Round } & & & -0.018 & -0.010 & $-0.111 *$ & $-0.080 *$ & $-0.061^{*}$ & $-0.047^{*}$ \\
\hline & & & $(0.004)$ & $(0.004)$ & $(0.004)$ & $(0.003)$ & $(0.004)$ & $(0.004)$ \\
\hline \multirow[t]{2}{*}{ Upstream Users Behavior Inv } & & & $-0.583^{*}$ & $-0.398 *$ & & & 0.642 & 0.387 \\
\hline & & & $(0.059)$ & $(0.075)$ & $0.742 *$ & & $(2.443)$ & (1.533) \\
\hline \multirow[t]{2}{*}{ Upstream Users Behavior Ext } & & & & & $(0.155)$ & $0.869 *$ & 0.239 & 0.321 \\
\hline & & & & & & $(0.307)$ & $(7.353)$ & $(10.268)$ \\
\hline \multirow[t]{2}{*}{ Gini Investment $t_{t-1}{ }^{++}$} & & & $-0.362 *$ & $0.620^{*}$ & & & $-0.469 *$ & $-0.283 *$ \\
\hline & & & $(0.165)$ & (0.349) & & & $(0.107)$ & $(0.114)$ \\
\hline \multirow[t]{2}{*}{ Gini Investment $\mathrm{t}_{\mathrm{t}-2}^{++}$} & & & $-0.194 *$ & $0.332 *$ & & & & \\
\hline & & & $(0.158)$ & $(0.323)$ & & & & \\
\hline \multirow[t]{2}{*}{ Gini Extraction $_{\mathrm{t}-1}{ }^{++}$} & & & & & $0.038^{*}$ & $0.044 *$ & $-0.127^{*}$ & $-0.171 *$ \\
\hline & & & & & $(0.066)$ & $(0.083)$ & $(0.055)$ & $(0.055)$ \\
\hline \multirow[t]{2}{*}{ Gini Extraction $_{\mathrm{t}-2^{++}}$} & & & & & $-0.243^{*}$ & $-0.284^{*}$ & & \\
\hline & & & & & $(0.079)$ & $(0.081$ & & \\
\hline $\mathrm{N}$ & \multicolumn{2}{|c|}{80} & \multicolumn{2}{|c|}{1040} & \multicolumn{2}{|c|}{1040} & 11 & \\
\hline $\mathrm{Chi}^{2} \mathrm{p}$-value & $\mathrm{n}$. & & 0.0 & & & & & \\
\hline Overall $R^{2}$ & 0.6 & & 0.9 & & & & & \\
\hline Discrepancy & 0.0 & & 0.2 & & & & & \\
\hline
\end{tabular}

Note: $*$ = significant at the $95 \%$ level, bootstrapped standard errors in parenthesis. All coefficients are standardized and represent total effect. $+\mathrm{e}=$ Indirect effect due to Investment on Extraction $++=$ Indirect effect due to Observed behavior. Position is compared to Position A, Treatment is comparing LHN and NHL to NLH. Rainfall is compared to low rainfall and Variability to no Variability. 
Table S4: Summary for system coefficients at the Individual Level

\begin{tabular}{|c|c|c|c|c|c|c|c|c|c|c|c|c|c|c|c|c|}
\hline \multirow[b]{2}{*}{ Variable } & \multicolumn{8}{|c|}{ Investment } & \multicolumn{8}{|c|}{ Extraction } \\
\hline & $\mathbf{R 1}$ & avg & $\min$ & $\max$ & Sign+ & Sign- & Sig & $\mathbf{N}$ & R1 & avg & $\min$ & $\max$ & Sign+ & Sign- & Sig & $\mathbf{N}$ \\
\hline Extraction $(\mathrm{t}-1)^{+e}$ & & 1.874 & 0.371 & 2.667 & 1.000 & 0.000 & 1.000 & 3 & & 0.378 & 0.116 & 0.760 & 1.000 & 0.000 & 1.000 & 3 \\
\hline Investment & & & & & & & & & -0.556 & 0.419 & 0.282 & 0.666 & 1.000 & 0.000 & 1.000 & 3 \\
\hline Position B & 0.053 & -0.027 & -0.054 & -0.012 & 0.000 & 1.000 & 0.333 & 3 & -0.078 & -0.034 & -0.079 & -0.006 & 0.000 & 1.000 & 0.333 & 3 \\
\hline Position C & -0.047 & -0.025 & -0.064 & -0.005 & 0.000 & 1.000 & 0.333 & 3 & -0.009 & 0.002 & -0.048 & 0.042 & 0.667 & 0.333 & 0.667 & 3 \\
\hline Position D & -0.017 & -0.100 & -0.186 & -0.055 & 0.000 & 1.000 & 1.000 & 3 & -0.277 & -0.069 & -0.140 & -0.018 & 0.000 & 1.000 & 0.667 & 3 \\
\hline Position E & -0.268 & -0.148 & -0.271 & -0.086 & 0.000 & 1.000 & 1.000 & 3 & -0.376 & -0.106 & -0.184 & -0.050 & 0.000 & 1.000 & 1.000 & 3 \\
\hline $\mathrm{NLH}^{*}$ LowVar $^{+e}$ & & 0.044 & 0.042 & 0.048 & 1.000 & 0.000 & 0.333 & 3 & & 0.017 & 0.005 & 0.036 & 0.667 & 0.000 & 0.333 & 3 \\
\hline $\mathrm{NLH}^{*} \mathrm{HighVar}^{+\mathrm{e}}$ & & 0.003 & -0.013 & 0.018 & 0.667 & 0.333 & 0.000 & 3 & & 0.004 & -0.003 & 0.014 & 0.333 & 0.333 & 0.000 & 3 \\
\hline LHNorNHL*NoVar+e & & -0.126 & -0.215 & -0.077 & 0.000 & 1.000 & 1.000 & 3 & & -0.065 & -0.163 & -0.009 & 0.000 & 1.000 & 1.000 & 3 \\
\hline LHNorNHL* LowVar ${ }^{+e}$ & -0.058 & -0.079 & -0.113 & -0.048 & 0.000 & 1.000 & 1.000 & 3 & 0.032 & -0.037 & -0.086 & -0.006 & 0.000 & 1.000 & 0.667 & 3 \\
\hline LHNorNHL*HighVar+e & -0.338 & -0.102 & -0.184 & -0.054 & 0.000 & 1.000 & 1.000 & 3 & 0.188 & -0.054 & -0.140 & -0.006 & 0.000 & 1.000 & 0.667 & 3 \\
\hline Normal Rainfall & & & & & & & & & & 0.316 & 0.314 & 0.317 & 1.000 & 0.000 & 1.000 & 3 \\
\hline High Rainfall & & & & & & & & & 0.587 & 0.460 & 0.440 & 0.482 & 1.000 & 0.000 & 1.000 & 3 \\
\hline Normalized Risk Scores ${ }^{+e}$ & 0.102 & 0.008 & -0.007 & 0.025 & 0.333 & 0.333 & 0.000 & 3 & -0.057 & 0.007 & -0.001 & 0.019 & 0.667 & 0.333 & 0.000 & 3 \\
\hline Trust+e & 0.378 & 0.007 & -0.010 & 0.036 & 0.333 & 0.333 & 0.333 & 3 & -0.210 & 0.008 & -0.003 & 0.027 & 0.333 & 0.667 & 0.333 & 3 \\
\hline Trustworthiness & & & & & & & & & 0.108 & -0.028 & -0.045 & -0.015 & 0.000 & 0.667 & 0.333 & 3 \\
\hline Round & & 0.723 & -0.100 & 2.333 & 0.333 & 0.667 & 1.000 & 3 & & -0.048 & -0.091 & -0.011 & 0.000 & 0.667 & 0.667 & 3 \\
\hline UUB NG & & -0.045 & -0.166 & 0.036 & 0.333 & 0.333 & 0.333 & 3 & & 0.693 & 0.625 & 0.760 & 1.000 & 0.000 & 0.500 & 2 \\
\hline UUB ESR & & 1.218 & -0.066 & 2.501 & 0.500 & 0.500 & 0.500 & 2 & & 0.070 & 0.002 & 0.138 & 0.500 & 0.000 & 0.500 & 2 \\
\hline Netgain $(\mathrm{t}-1)^{++}$ & & -2.341 & -2.399 & -2.283 & 0.000 & 0.500 & 1.000 & 2 & & -0.069 & -0.135 & -0.002 & 0.000 & 1.000 & 0.500 & 2 \\
\hline Netgain $(\mathrm{t}-2)^{++}$ & & -0.086 & -0.091 & -0.081 & 0.000 & 0.500 & 1.000 & 2 & & -0.003 & -0.005 & 0.000 & 0.000 & 0.500 & 0.500 & 2 \\
\hline $\operatorname{ESR}(\mathrm{t}-1)^{++}$ & & -0.013 & -0.032 & 0.007 & 0.500 & 0.500 & 0.500 & 2 & & 0.132 & 0.115 & 0.148 & 1.000 & 0.000 & 1.000 & 2 \\
\hline $\operatorname{ESR}(\mathrm{t}-2)^{++}$ & & -0.021 & -0.055 & 0.014 & 0.500 & 0.500 & 0.500 & 2 & & 0.248 & 0.242 & 0.254 & 1.000 & 0.000 & 1.000 & 2 \\
\hline
\end{tabular}

Note: $\mathrm{R} 1=$ effects on round $1 .++=$ effects given indirectly due to the Observation variable. $+\mathrm{e}=$ Indirect effect on extraction, but direct on

investment. Avg, min, max = average, minimum and maximum coefficient estimated (exclude R1 estimates). Sign + and Sign - indicate the fraction of times that the coefficient was positive or negative. Sig = fraction of times a coefficient was significant. $\mathrm{N}=$ number of models in which a variable was estimated 
Table S5: Summary for system coefficients at the Group Level

\begin{tabular}{|c|c|c|c|c|c|c|c|c|c|c|c|c|c|c|c|c|}
\hline \multirow{2}{*}{ Variable } & \multicolumn{8}{|c|}{ Investment } & \multicolumn{8}{|c|}{ Extraction } \\
\hline & $\mathbf{R 1}$ & avg & $\min$ & $\max$ & sign + & sign - & sig & $\mathbf{N}$ & R1 & avg & $\min$ & $\max$ & sign + & sign - & sig & $\mathbf{N}$ \\
\hline Avg Extraction ${ }_{\mathrm{t}-1}+\mathrm{e}$ & & 0.289 & 0.195 & 0.431 & 1.000 & 0.000 & 1.000 & 3 & & 0.214 & 0.156 & 0.289 & 1.000 & 0.000 & 1.000 & 3 \\
\hline Low Variability $^{+e}$ & 0.570 & 0.057 & 0.034 & 0.092 & 1.000 & 0.000 & 0.667 & 3 & 0.321 & 0.044 & 0.023 & 0.076 & 1.000 & 0.000 & 0.667 & 3 \\
\hline High Variability ${ }^{+e}$ & & 0.084 & 0.065 & 0.099 & 1.000 & 0.000 & 1.000 & 3 & & 0.064 & 0.053 & 0.071 & 1.000 & 0.000 & 1.000 & 3 \\
\hline Normal Rainfall & & & & & & & & & & 0.440 & 0.434 & 0.446 & 1.000 & 0.000 & 1.000 & 3 \\
\hline High Rainfall & & & & & & & & & 0.478 & 0.751 & 0.748 & 0.754 & 1.000 & 0.000 & 1.000 & 3 \\
\hline Treatment $^{+\mathrm{e}}$ & -0.706 & -0.139 & -0.215 & -0.093 & 0.000 & 1.000 & 1.000 & 3 & -0.398 & -0.102 & -0.144 & -0.076 & 0.000 & 1.000 & 1.000 & 3 \\
\hline Avg Normalized Risk Scores ${ }^{+\mathrm{e}}$ & -0.032 & 0.224 & 0.145 & 0.307 & 1.000 & 0.000 & 1.000 & 3 & -0.018 & 0.167 & 0.118 & 0.206 & 1.000 & 0.000 & 1.000 & 3 \\
\hline Avg Trust ${ }^{+e}$ & -0.223 & 0.075 & 0.066 & 0.087 & 1.000 & 0.000 & 1.000 & 3 & -0.125 & 0.058 & 0.044 & 0.069 & 1.000 & 0.000 & 1.000 & 3 \\
\hline Avg Trustworthiness & & & & & & & & & -0.062 & 0.010 & 0.001 & 0.022 & 1.000 & 0.000 & 0.333 & 3 \\
\hline Round & & -0.063 & -0.111 & -0.018 & 0.000 & 1.000 & 0.667 & 3 & & -0.045 & -0.080 & -0.010 & 0.000 & 1.000 & 0.667 & 3 \\
\hline Upstream users behavior Ext & & 0.197 & 0.155 & 0.239 & 1.000 & 0.000 & 0.000 & 2 & & 0.595 & 0.321 & 0.869 & 1.000 & 0.000 & 0.500 & 2 \\
\hline Upstream users behavior Inv & & 0.029 & -0.583 & 0.642 & 0.500 & 0.500 & 0.500 & 2 & & -0.005 & -0.398 & 0.387 & 0.500 & 0.500 & 0.500 & 2 \\
\hline Gini Extraction $\mathrm{t}-1^{++}$ & & -0.045 & -0.127 & 0.038 & 0.500 & 0.500 & 1.000 & 2 & & -0.063 & -0.171 & 0.044 & 0.500 & 0.500 & 1.000 & 2 \\
\hline Gini Extractiont-2 ${ }^{++}$ & & -0.243 & -0.243 & -0.243 & 0.000 & 1.000 & 1.000 & 1 & & -0.284 & -0.284 & -0.284 & 0.000 & 1.000 & 1.000 & 1 \\
\hline Gini Investment $t_{-1}^{++}$ & & -0.415 & -0.469 & -0.362 & 0.000 & 1.000 & 1.000 & 2 & & 0.168 & -0.283 & 0.620 & 0.500 & 0.500 & 1.000 & 2 \\
\hline Gini Investment $t-2^{++}$ & & -0.194 & -0.194 & -0.194 & 0.000 & 1.000 & 1.000 & 1 & & 0.332 & 0.332 & 0.332 & 1.000 & 0.000 & 1.000 & 1 \\
\hline
\end{tabular}

Note: $++=$ effects given indirectly due to the Observation variable. $+\mathrm{e}=$ Indirect effect on extraction, but direct on investment. Avg, min, max $=$ average, minimum and maximum coefficient estimated. Sig + and Sig - indicate the fraction of times that the coefficient was positive or negative. Sig = fraction of times a coefficient was significant. $\mathrm{N}=$ number of models in which a variable was estimated. 


\section{Experiment Instructions and Forms}

Italic: instructions for the experimenters

Normal: instructions read out loud for the participants

When people show up they sign consent form. Participants are seated in groups of 5, their positions determined randomly. When people are seated they are requested to complete the two exercise forms.

Welcome to the experiment. We will complete a number of exercises. You will be rewarded by cash payments at the end of the experiment based on the decisions you have made. Before we begin I ask you to turn off your mobile phones and other mobile devices so we will not be disturbed during the experiment.

We will now give you two exercises which you are asked to fill out. Please read the instructions carefully since your decisions will affect how much money you can earn. If you have questions raise your hand and we will address your question.

Exercise 1. Risk aversion

Exercise 2. Trust games

When the forms are collected, we will proceed to the irrigation experiment

\section{Exercise 1}

This exercise sheet lists ten decisions. Each decision is a paired choice between "Option A" and "Option B." You will make ten choices and record these in the final column, but only one of these choices will be used in the end to determine your earnings. Before you start making your ten choices, please let me explain how these choices will affect your earnings for this part of the experiment.

We will use a ten-sided die to determine the payoffs; the faces are numbered from 1 to 10 . After you have made all of your choices, we will throw this die twice, once to select one of the ten decisions to be used, and a second time to determine what your payoff is for the option you chose, A or B, for the particular decision selected. Even though you will make ten decisions, only one of these will end up affecting your earnings, but you will not know in advance which decision will be used. Obviously, each decision has an equal chance of being used in the end.

Now, please look at Decision 1 at the top. Option A pays $\$ 2.00$ if the throw of the ten sided die is 1 and it pays $\$ 1.60$ if the throw is $2-10$. Option B yields $\$ 3.85$ if the throw of the die is 1 , and it pays $\$ 0.10$ if the throw is $2-$ 10. The other Decisions are similar, except that as you move down the table, the chances of the higher payoff for each option increase. In fact, for Decision 10 in the bottom row, the die will not be needed since each option always pays the highest payoff, so your choice here is between $\$ 2.00$ or $\$ 3.85$.

To summarize, you will make ten choices: for each decision row you have to choose between Option A or Option B. You may choose A for some decision rows and B for other rows, and you may change your decisions and make them in any order. When you are finished, we will collect the forms. When we pay you your earnings at the end of today's exercises, we will throw the ten-sided die to select which of the ten Decisions 
will be used, and a second time to determine your money earnings for the Option you chose for that Decision. Earnings for this choice will be added to your other earnings, and you will be paid all earnings in cash.

So now please fill in each of the empty boxes on the right side of the record sheet. You need to enter your choice, A or B, in each of these boxes.

Are there any questions? Now you may begin making your choices. Please do not talk with anyone while we are doing this; raise your hand if you have a question.

\begin{tabular}{|l|l|l|l|}
\hline Die & \multicolumn{1}{|c|}{ Option A } & \multicolumn{1}{|c|}{ Option B } & \multicolumn{1}{|c|}{$\begin{array}{c}\text { Your Choice } \\
\text { (A or B) }\end{array}$} \\
\hline 1 & $\$ 2.00-1$ & $\$ 3.85-1$ & \\
& $\$ 1.60-2,3,4,5,6,7,8,9,10$ & $\$ 0.10-2,3,4,5,6,7,8,9,10$ & \\
\hline 2 & $\$ 2.00-1,2$ & $\$ 3.85-1,2$ & \\
& $\$ 1.60-3,4,5,6,7,8,9,10$ & $\$ 0.10-3,4,5,6,7,8,9,10$ & \\
\hline 3 & $\$ 2.00-1,2,3$ & $\$ 3.85-1,2,3$ & \\
& $\$ 1.60-4,5,6,7,8,9,10$ & $\$ 0.10-4,5,6,7,8,9,10$ & \\
\hline 4 & $\$ 2.00-1,2,3,4$ & $\$ 3.85-1,2,3,4$ & \\
& $\$ 1.60-5,6,7,8,9,10$ & $\$ 0.10-5,6,7,8,9,10$ & \\
\hline 5 & $\$ 2.00-1,2,3,4,5$ & $\$ 3.85-1,2,3,4,5$ & \\
& $\$ 1.60-6,7,8,9,10$ & $\$ 0.10-6,7,8,9,10$ & \\
\hline 6 & $\$ 2.00-1,2,3,4,5,6$ & $\$ 3.85-1,2,3,4,5,6$ & \\
& $\$ 1.60-7,8,9,10$ & $\$ 0.10-7,8,9,10$ & \\
\hline 7 & $\$ 2.00-1,2,3,4,5,6,7$ & $\$ 3.85-1,2,3,4,5,6,7$ & \\
& $\$ 1.60-8,9,10$ & $\$ 0.10-8,9,10$ & \\
\hline 8 & $\$ 2.00-1,2,3,4,5,6,7,8$ & $\$ 3.85-1,2,3,4,5,6,7,8$ & \\
& $\$ 1.60-9,10$ & $\$ 0.10-9,10$ & \\
\hline 9 & $\$ 2.00-1,2,3,4,5,6,7,8,9$ & $\$ 3.85-1,2,3,4,5,6,7,8,9$ & \\
& $\$ 1.60-10$ & $\$ 0.10-10$ & \\
\hline 10 & $\$ 2.00-1,2,3,4,5,6,7,8,9,10$ & $\$ 3.85-1,2,3,4,5,6,7,8,9,10$ & \\
& & & \\
\hline
\end{tabular}




\section{Exercise 2}

In this exercise you will be randomly matched with another person in this room, but you will not know who that person is. That person will also not know who you are. You must write down your decisions for the possibility if you are selected to be Player 1 in this exercise or if you are selected to be Player 2.

The person randomly selected to be Player 1 has the following decision to make: You will receive 3 dollars and must decide how much to keep for yourself and how much to send to Player 2 in this room.

The amount you send to Player 2 will be tripled and then given to Player 2 . Player 2 will decide how much to keep and how much to send back to you. For example, if you, Player 1, send 0 dollars to player 2, 0 dollars will be sent to player 2 and you will keep 3 dollars for yourself. However, if you choose to send 3 dollars to Player 2 , those 3 dollars will be multiplied into 9 dollars and sent to Player 2. Player 2 would then decide how much to return to you.

Player 2 has the following decision to make: You have to choose for each of the 4 possible cases, how much to keep for yourself and how much to send back to player 1.

Please complete both tables for Player 1 AND for Player 2. We will randomly select whether you are Player 1 or Player 2 after we receive all these forms.

Are there any questions? If you have a question, raise your hand and I will try to answer it.

Player 1: Please check ONE of the following allocations.

\begin{tabular}{|c|c|c|c|}
\hline Dollars kept by you & Dollars send to other & Received by other & Check One Row \\
\hline$\$ 0$ & $\$ 3$ & $(3 \times \$ 3)=\$ 9$ & \\
\hline$\$ 1$ & $\$ 2$ & $(3 \times \$ 2)=\$ 6$ & \\
\hline$\$ 2$ & $\$ 1$ & $(3 \times \$ 1)=\$ 3$ & \\
\hline$\$ 3$ & $\$ 0$ & $(3 \times \$ 0)=\$ 0$ & \\
\hline
\end{tabular}

Player 2: Please enter your choice for ALL of the following allocations:

(column 3 and $\mathbf{4}$ must add up to column 2)

\begin{tabular}{|c|c|c|c|}
\hline Sent by other & Received from other & Kept by you & Send back to other \\
\hline$\$ 0$ & $(3 \times \$ 0)=\$ 0$ & $\$ 0$ & $\$ 0$ \\
\hline$\$ 1$ & $(3 \times \$ 1)=\$ 3$ & & \\
\hline$\$ 2$ & $(3 \times \$ 2)=\$ 6$ & & \\
\hline$\$ 3$ & $(3 \times \$ 3)=\$ 9$ & & \\
\hline
\end{tabular}




\section{INSTRUCTIONS FOR THE IRRIGATION GAME}

\section{Baseline Phase - No Variability}

This exercise is intended to recreate a situation in which people must make decisions about using water to irrigate land. You have been selected to participate in a group of five individuals. You will play several rounds, each of which is roughly equivalent to an agricultural year or irrigation season.

In each round, you will have to make two decisions. First, each of you will have to decide how much to contribute into a public fund to maintain the irrigation canal. The sum of all the contributions to the fund will determine the quantity of water units that will be available to your group. In the second decision, you will take turns extracting water units from the system. Each unit you collect during the game is equivalent to 5 cents. For example, if you collect 200 units during the game, you will receive $\$ 10$.

We will now discuss the first decision in detail. Each round, you will begin with 10 units to spend. You have to decide how many of those units to contribute into the public fund and how many to keep for yourself. You can think of this as the amount of labor you might invest into the maintenance of the irrigation system. The amount of effort you may contribute is between 0 and 10 units. You will enter your contribution quantity onto your Decision Form in Column A.

We will write down your contribution decision and calculate the quantity of water units available to the group using the TABLE OF AVAILABLE WATER QUANTITY, which you have for reference. This payoff table shows you how the available water quantity is calculated based upon the size of the public fund, from your contribution and those of the other 4 players in your group.

Once we have recorded your contribution decisions and calculated the quantity of available water, we will write that quantity onto your Decision Form in Column B.

So, for example, if everyone were to contribute 2 units to the public fund and kept 8 units for themselves, no water would be available to be distributed to the group. As a result, everyone would end up with 8 units at the end of the round.

In another example, if everyone were to invest 10 units into the public fund, 100 units of water would be available to be distributed to the group.

Keep in mind that decisions are private, and everyone can decide how much they want to invest into the public fund.

Once the total water quantity has been written onto your decision form, each individual in your group will take turns in deciding how much water to extract from the irrigation system. In this experiment, everyone has the same size of land to be irrigated. The amount of money that you will earn is directly dependent upon the amount of water you take from the system.

After you signed in today, you drew a random card labeled with your group number and a letter, A, B, C, D, or E. That card determined your position within your group.

Your group will take turns in deciding how much water to take for irrigating their land. These turns are determined by the letter of the card you received, which indicates your position in the irrigation system. 
This means that first, player A decides how much water to take and writes down that decision onto the Decision Form in Column C. We will record that decision and subtract the taken water from the available water for player $\mathrm{B}$. We will write down the remaining available water quantity and show this number to player B so they can take their turn and decide how much water to take. Each player takes their turn in this manner until player $E$ has written down their decision.

[example: The instructor shows what happens if first player A takes from the pool, then $B$, etc.]

You may keep track of your earnings each round by filling in Columns $D$ and $E$ on your Decision Form. Column $D$ is the amount of units you kept for yourself instead of investing into the public fund. Column $E$ is your earnings for the round, which is the sum of the water you extracted plus the units you kept in the first decision.

The next round begins with your decisions on the contributions to the public fund as in the previous round.

It is very important to keep in mind that your decisions are absolutely individual. This means that the numbers you write down on the forms are private and you must not show them or discuss them with the other members of the group.

Are there any questions about this? [MONITOR: pause to resolve questions.]

Remember that the units you earn depend on your own decisions, and they will become money at the end of this exercise.

Keep in mind that from now on you are not allowed to talk unless I give you permission.

We will have one practice round that will NOT count for your real earnings. It is just an opportunity for you to familiarize yourself with the game. For this practice round, contribute 5 units into the public fund.

We will now record your contribution decisions.

Because everyone contributed 5 units, resulting in 25 units in the public fund, 40 units of water are available to the group.

Now you will take turns in deciding how much water to extract from the system, beginning with player $A$.

We will now start the actual experiment

[continue with phase.] 


\section{Low Variability Phase}

It is time to make one change to the game. A new payoff table will be handed out. Now, each round has the possibility of having a low, medium, or high level of rainfall, which will affect the amount of water that the irrigation system can produce. Medium rainfall produces the normal amount of water in the irrigation system as was used in the previous rounds. However, if a round has low rainfall, the amount of water generated for a given quantity of contributions will be lower than in a normal round. If the round has high rainfall, the amount of water generated will be higher than normal.

After all contributions into the public fund have recorded, the rainfall level will be announced. To determine whether each of the upcoming rounds will have low, medium, or high rainfall, a 6-sided die was rolled and recorded. If the die was a 1 , the round will be a low rainfall. If the die was a 6 , the round will be a high rainfall. If the die was a 2 through 5 , then the round will be medium rainfall. Therefore, there is a 1 in 6 chance for a round to be low rainfall, 1 in 6 chance for a round to be high rainfall, and a 4 in 6 chance for a normal month. After the rainfall level is announced, the amount of water available to the group will be written onto your decision forms, and the second part of the round will continue.

\section{High Variability Phase}

It is time to make another change to the game. We will continue to use the same payoff table as before, but this time, if the die was a 1 or 2 , the round will be low rainfall. If it was a 3 or 4 , then the round will be medium rainfall, and if the die was a 5 or 6 , the round will be high rainfall. Each type of round has an equal chance of 1 in 3 in occurring. After the rainfall level is announced, the amount of water available to the group will be written onto your decision forms, and the second part of the round will continue. 
Information provided to Participants: Table of Water availability

\begin{tabular}{|cccc|}
\hline \multicolumn{4}{|c|}{ Table of available water quantity } \\
\hline $\begin{array}{c}\text { Total units } \\
\text { invested in } \\
\text { the public } \\
\text { fund by all } 5 \\
\text { players }\end{array}$ & Low & Middle & High \\
\hline $0-10$ & 0 & 0 & 0 \\
\hline $11-15$ & 2 & 5 & 8 \\
\hline $16-20$ & 8 & 20 & 32 \\
\hline $21-25$ & 16 & 40 & 64 \\
\hline $26-30$ & 24 & 60 & 96 \\
\hline $31-35$ & 30 & 75 & 120 \\
\hline $36-40$ & 34 & 85 & 136 \\
\hline $41-45$ & 38 & 95 & 152 \\
\hline $46-50$ & 40 & 100 & 160 \\
\hline
\end{tabular}

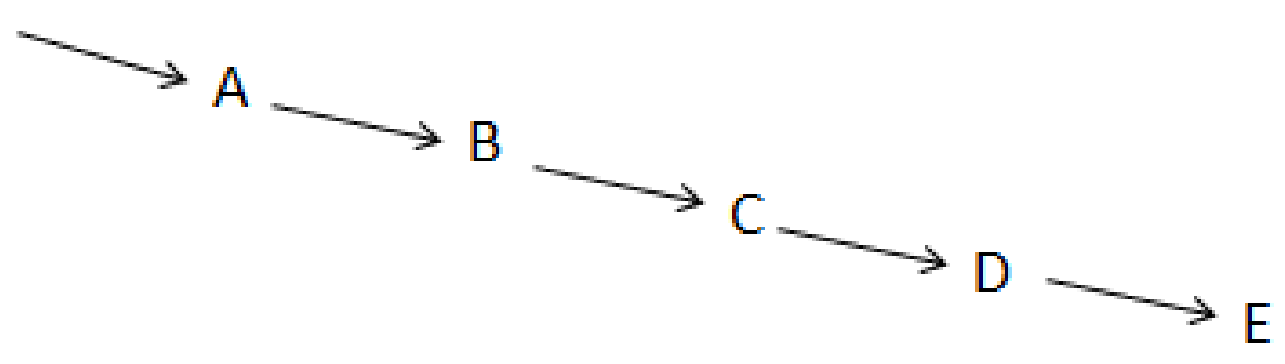


Participant Decision Form

Player no:

Capital letter: Round

\begin{tabular}{|l|l|l|l|l|l|}
\hline \multicolumn{2}{|c}{ A } & \multicolumn{1}{c|}{ B } & D \\
\hline & Contribution & $\begin{array}{c}\text { Water } \\
\text { for group }\end{array}$ & $\begin{array}{c}\text { Amount } \\
\text { extracted }\end{array}$ & $\begin{array}{c}\text { Amount } \\
\text { kept }= \\
\text { 10-A }\end{array}$ & $\begin{array}{c}\text { Earnings: } \\
\text { C+D }\end{array}$ \\
\hline Practice & & & & & \\
\hline 1 & & & & & \\
\hline 2 & & & & & \\
\hline 3 & & & & & \\
\hline 4 & & & & & \\
\hline 5 & & & & & \\
\hline 6 & & & & & \\
\hline 7 & & & & & \\
\hline 8 & & & & & \\
\hline 9 & & & & & \\
\hline 10 & & & & & \\
\hline 11 & & & & & \\
\hline 12 & & & & & \\
\hline 13 & & & & & \\
\hline 14 & & & & & \\
\hline 15 & & & & & \\
\hline 16 & & & & & \\
\hline 17 & & & & & \\
\hline 18 & & & & & \\
\hline
\end{tabular}




\section{INDIVIDUAL SURVEY}

Participant ID:

1. How old are you? years

2. Sex $\square$ Male $\square$ Female

3. What is your major?:

4. Year of study (chose one option)
\begin{tabular}{|l|}
$\square$ \\
\hline$\square$ \\
\hline$\square$ \\
$\square$ \\
\hline$\square$
\end{tabular}
1. Freshman
2. Sophomore
3. Junior
4. Senior
5. Graduate student

5. How satisfied were you with the earnings during the exercises?
\begin{tabular}{|l|}
$\square$ \\
\hline$\square$ \\
\hline$\square$ \\
\hline$\square$
\end{tabular}
1. I was completely dissatisfied
2. I was not satisfied
3. I was somewhat satisfied
4. I was satisfied
5. I was very satisfied

6. Did you understand the instructions of the exercises?
\begin{tabular}{|l|}
$\square$ \\
\hline$\square$ \\
\hline$\square$ \\
\hline$\square$ \\
\hline$\square$
\end{tabular}
1. I did not understood anything
2. I did understand only a bit of the instructions
3. I did understood half of the instructions
4. I did understood most of the instructions
5. I did understood everything

7. Have you ever voted in an election (including student governance elections)?
$\square$ 1. yes
$\square \quad$ 2. No

8. Global warming is a fact and is mostly caused by emissions from vehicles and industrial facilities.
$\square \quad 1$ I I completely agree
2. I somewhat agree
3. I have no opinion
4. I somewhat disagree
5. I completely disagree 
9. The federal Government should manage the U.S. economy.

1. I completely agree

2. I somewhat agree

3. I have no opinion

4. I somewhat disagree

5. I completely disagree

10. Tell me whether the first statement or the second statement comes closer to your own views - even if neither is exactly right.

$\square$ 1. Most people who want to get ahead can make it if they're willing to work hard

OR

2. Hard work and determination are no guarantee of success for most people

11. Tell me whether the first statement or the second statement comes closer to your own views - even if neither is exactly right.

$\square \quad$ 1. The government should do more to help needy Americans, even if it means going deeper into debt

OR

2. The government today can't afford to do much more to help the needy

12. Aside from weddings and funerals, how often do you attend religious services

1. More than once a week

2. Once a week

3. Once or twice a month

4. A few times a year

5. Seldom

6. Never

13. How important is religion in your life

1. Very important

2. Somewhat important

3. Not too important

4. Not at all important

5. Don't know

14. Please provide any comments on the experiment you have. 